\title{
Multifunctional Superparamagnetic Stiff Nanoreservoirs for Blood Brain Barrier Applications
}

\author{
Zulema Vargas-Osorio ${ }^{1}$ (D), Andrés Da Silva-Candal ${ }^{2, *}$, Yolanda Piñeiro ${ }^{1, *}$, Ramón Iglesias-Rey ${ }^{2}$, \\ Tomas Sobrino $^{2}$, Francisco Campos ${ }^{2}$, José Castillo ${ }^{2}$ and José Rivas ${ }^{1}$ \\ 1 NANOMAG Laboratory, Applied Physics Department, Universidade de Santiago de Compostela, \\ 15782 Santiago de Compostela, Spain; voz_wolverine74@hotmail.com (Z.V.-O.); jose.rivas@usc.es (J.R.) \\ 2 Clinical Neurosciences Research Laboratory, Health Research Institute of Santiago de Compostela (IDIS), \\ Hospital Clínico Universitario, Universidade de Santiago de Compostela, 15706 Santiago de Compostela, \\ Spain; Ramon.Iglesias.Rey@sergas.es (R.I.-R.); Tomas.Sobrino.Moreiras@sergas.es (T.S.); \\ Francisco.Campos.Perez@sergas.es (F.C.); Jose.Castillo.Sanchez@sergas.es (J.C.) \\ * Correspondence: Andres.Alexander.Da.Silva.Candal@sergas.es (A.D.S.-C.); y.pineiro.redondo@usc.es (Y.P.)
}

Received: 31 January 2019; Accepted: 12 March 2019; Published: 17 March 2019

check for updates

\begin{abstract}
Neurological diseases (Alzheimer's disease, Parkinson's disease, and stroke) are becoming a major concern for health systems in developed countries due to the increment of ageing in the population, and many resources are devoted to the development of new therapies and contrast agents for selective imaging. However, the strong isolation of the brain by the brain blood barrier (BBB) prevents not only the crossing of pathogens, but also a large set of beneficial drugs. Therefore, an alternative strategy is arising based on the anchoring to vascular endothelial cells of nanoplatforms working as delivery reservoirs. In this work, novel injectable mesoporous nanorods, wrapped by a fluorescent magnetic nanoparticles envelope, are proposed as biocompatible reservoirs with an extremely high loading capacity, surface versatility, and optimal morphology for enhanced grafting to vessels during their diffusive flow. Wet chemistry techniques allow for the development of mesoporous silica nanostructures with tailored properties, such as a fluorescent response suitable for optical studies, superparamagnetic behavior for magnetic resonance imaging MRI contrast, and large range ordered porosity for controlled delivery. In this work, fluorescent magnetic mesoporous nanorods were physicochemical characterized and tested in preliminary biological in vitro and in vivo experiments, showing a transversal relaxivitiy of $324.68 \mathrm{mM}^{-1} \mathrm{~s}^{-1}$, intense fluorescence, large specific surface area $\left(300 \mathrm{~m}^{2} \mathrm{~g}^{-1}\right)$, and biocompatibility for endothelial cells' uptake up to $100 \mu \mathrm{g}$ (in a $80 \%$ confluent $1.9 \mathrm{~cm}^{2}$ culture well), with no liver and kidney disability. These magnetic fluorescent nanostructures allow for multimodal MRI/optical imaging, the allocation of therapeutic moieties, and targeting of tissues with specific damage.
\end{abstract}

Keywords: theranostic nanostructure; MRI contrast; neurological diseases

\section{Introduction}

Improvements in imaging techniques, or new therapeutic paradigms, are behind the continuous evolution of medicine towards the objective of defeating diseases. Nanomedicine has become, in recent years, a field of growing demand and the use of nanotechnology allows an approach at the molecular level, the same length scale as biological events (nanometres), with a strong focus [1] on developing biomedical agents with less secondary effects than traditional pharmaceuticals.

Designed nanoparticles offer the possibility of incorporating within a single carrier complementary biomedical functions [2,3], like therapy, imaging, and tagging, which allows for detailed studies at precise locations or specific treatments that avoid systemic dosage. 
However, neurological diseases pose a great challenge in the field [4], in both the medical and scientific context, due to the intricate complexity of the central nervous system (CNS). The brain is a fragile organ composed of a dense network of billions of nerve cells, strongly protected by the blood brain barrier (BBB). Composed of tightly connected vascular endothelial cells, by adherents and junctions (TJs), and a sparse layer of pericytes, the BBB strictly regulates brain homeostasis [5]. This physiologic behavior is crucial for our survival, since mainly all pathogens are filtered out, but it is also the main hindrance for neuroscientific developments because it also filters out most drugs after systemic administration [6,7].

To facilitate the delivery and permeation of drugs to the brain, an emergent paradigm seeks to bind theranostic agents to the luminal plasma membrane of the BBB endothelial cells, thus using them as docking reservoirs. In this way, the binding to the endothelium allows nanoparticles to mark vessels affected by diverse cerebral pathologies with a vascular component and the development of targeting strategies to receptors that mediate transcytosis to allow the crossing of nanostructures through the BBB.

Although soft nanostructures (liposomes, thermoreversible polymers) have been preferred in the past as nanodelivery systems, their scarce colloidal stability and immune system response preclude them from being effective for clinical therapies. Therefore, there is a need of multifunctional nanocarriers with high biocompatibility and stability under forced flow or diffusion through highly viscous tissues for different in vivo applications. In this regard, mesoporous nanostructures combine a set of properties that ensure their suitable performance for different theranostic purposes, with the advantage of being chemically stable and resistant under variable $\mathrm{pH}$, temperature, and flow conditions.

Among their advantages, the following have been reported [8-10]: Low immune response, chemical resistance to enzymes [11]; prolonged drug release [12-15]; large surface area for gene transfection [16,17], bone regeneration [18,19], and multimode theranostic actions [20-22]; magnetic separators [23]; cell markers [24]; and supports for enzyme immobilization [25].

Moreover, enhanced biological advantages can be achieved by tailoring the intrinsic characteristics of mesoporous silica nanostructures [26], such as porosity, functionalization [27,28], size [29], and shape. Specifically, it has been reported that rod-like shaped mesoporous silica nanoparticles are well suited for monitoring cell trafficking [30], and their hydrophilic character facilitates the adhesion and functioning of several brain cell types [31].

In this work, the development, physicochemical study, and in vitro and in vivo tests of mesoporous silica nanorods are presented. Rod-like nanostructures with large pores $(\mathrm{d}=7 \mathrm{~nm})$ obtained by a soft template method were functionalized with amino groups and a fluorescent dye and coated with superparamagnetic magnetite NPs. Their physicochemical characterization shows a set of multifunctional abilities, like good colloidal stability, transversal relaxivitiy of $\mathrm{r}^{2}=324.68 \mathrm{mM}^{-1} \mathrm{~s}^{-1}$, intense fluorescence emission, and large porosity $\left(300 \mathrm{~m}^{2} \mathrm{~g}^{-1}\right)$. Biological characterizations show good biocompatibility for endothelial cell uptakes up to $100 \mu \mathrm{g} /$ culture plate for in vitro tests and no brain, liver, and kidney disability after in vivo administration.

This preliminary physicochemical and biological in vitro/in vivo study shows that magnetic mesoporous silica nanorods present a combination of properties that make them suitable candidates to be tested as multifunctional nanoreservoirs in brain endothelium applications.

\section{Materials and Methods}

\subsection{Chemicals and Synthesis Chemicals}

3-Aminopropyl(diethoxy)methylsilane ( $\geq 97 \%$ ), tetraethyl orthosilicate $(98 \%)$, iron(III) chloride hexahydrate $(97 \%)$, hydrochloric acid $(37 \%)$, phosphoric acid $(85 \%)$, cyclohexane $(99.8 \%)$, Igepal CO-520 [Polyoxyethylene (5) nonylphenylether, branched], glycerol solution (86-89\%), Pluronic ${ }^{\circledR}$ P123[triblock-copolymer-PEO $20: \mathrm{PPO}_{70}: \mathrm{PEO}_{20}$,Poly(ethyleneglycol)-block-poly(propyleneglycol)-block- 
poly(ethyleneglycol)], average $\mathrm{M}_{\mathrm{n}} \approx 5800$ ), Rhodamine B isothiocyanate (C29H30CIN3O3S, RBITC), isooctane $\left(\mathrm{C}_{8} \mathrm{H}_{18} \geq 99 \%\right)$, 2-propanol ( $\geq 99.5 \%$, IPA), Tween ${ }^{\circledR} 20$ (viscous liquid, polyethylene glycol sorbitan monolaurate), paraformaldehyde (PFA, reagent grade, crystalline), and potassium hexacyanoferrate(II) trihydrate (ACS reagent, 98.5-102.0\%) were obtained from Sigma Aldrich (3050 Spruce Street, Saint Louis, MO, USA); iron(II) sulfate heptahydrate (99\%) and ammonium hydroxide (28\%) from Fluka Analytical (Honeywell Fluka ${ }^{\mathrm{TM}}$, Morris Plains, NJ, USA); oleic acid (extra pure) from Merck (Darmstadt, Germany); ethanol (99.9\%) and acetone ( $\geq 99 \%$ ) were purchased at Scharlau (Senmanat, Spain). Phosphate buffer solution (PBS, pH 7.4), Dulbecco's Modified Eagle Medium (DMEM), fetal bovine serum, and penicillin-streptomicin from Gibco-Invitrogen,

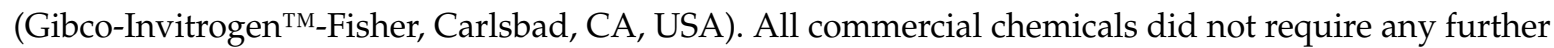
purification. All water utilized in the experiments was Milli-Q (Millipore ${ }^{\circledR}$, Burlington, MA, USA) deionized water.

\subsection{Synthesis of Fluorescent Magnetic Mesoporous Nanorods}

Rod-like SBA-15 mesoporous silica (S15N nanorods) were prepared following the method used by Wang and coworkers [32]. Triblock copolymer, Pluronic P123, was used as a template in the presence of glycerol solution, while tetraethyl orthosilicate (TEOS) was the silicate precursor in acidic conditions. In a typical synthesis, $7.8 \mathrm{~g}$ of both $\mathrm{P} 123$ and glycerol were dissolved in $300 \mathrm{~g}$ of an aqueous acidic solution $2 \mathrm{M}$ of $\mathrm{HCl} / \mathrm{H}_{3} \mathrm{PO}_{4}(2: 1)$. The mixture was stirred at $35^{\circ} \mathrm{C}$ until the surfactant was completely dissolved. Then, $16.4 \mathrm{~mL}$ TEOS $(80.61 \mathrm{mmol})$ was added to the above solution under vigorous magnetic stirring. After $10 \mathrm{~min}$, the stirring was stopped, and the reaction continued in static conditions for $24 \mathrm{~h}$, followed by aging at $100{ }^{\circ} \mathrm{C}$ for $24 \mathrm{~h}$. The final product was filtrated, washed with water, and dried at $60^{\circ} \mathrm{C}$. The resulting material was extracted with a mix of isooctane/ethanol and water/acetone to remove the surfactant. Magnetite nanoparticles (NPs) were obtained by the coprecipitation method, in which $90 \mathrm{mmol}$ of $\mathrm{FeCl}_{3} \cdot 6 \mathrm{H}_{2} \mathrm{O}$ and $60 \mathrm{mmol}$ of $\mathrm{FeSO}_{4} \cdot 7 \mathrm{H}_{2} \mathrm{O}$ were dissolved in $200 \mathrm{~mL}$ of $0.01 \mathrm{M} \mathrm{HCl}$ aqueous solution and mechanically stirred. The mixture was heated up to $60{ }^{\circ} \mathrm{C}$, then $1500 \mathrm{mmol}$ of $\mathrm{NH}_{4} \mathrm{OH}$ and $14.2 \mathrm{mmol}$ of oleic acid were added, and the reaction was carried out for $1 \mathrm{~h}$. After that, the sample was transferred to a beaker and placed on a hot plate at $100{ }^{\circ} \mathrm{C}$ to allow for precipitation. The precipitate containing oleic acid-capped magnetite nanoparticles $\left[\mathrm{Fe}_{3} \mathrm{O}_{4} @ \mathrm{OA}\right], \mathrm{OAM}$, was retained with a magnet and the supernatant was removed. OAM were washed three times with deionized water.

Afterwards, magnetic S15N nanorods, HMMSN, were obtained by covalently anchoring magnetite NPs over mesoporous silica nanorods [33]. For this, a previously prepared solution (2.4 mL) of oleic acid-capped magnetite nanoparticles $\left[\mathrm{Fe}_{3} \mathrm{O}_{4} @ \mathrm{OA}\right]$ stabilized in cyclohexane at $3.5 \%(w / v)$ was poured into a $7.6 \%$ solution of Igepal CO-520 in cyclohexane $(266.16 \mathrm{mmol})$, at a 1:12.5 volume ratio, and stirred for $30 \mathrm{~min}$. Then, $12.56 \mathrm{mmol}$ of $\mathrm{NH}_{4} \mathrm{OH}$ and $0.5 \mathrm{~g}$ of S15N nanorods were added to the mixture and stirred for $40 \mathrm{~min}$ until the amino functional coupling agent $(1.35 \mathrm{mmol})$ was dispensed dropwise into the mixture. After keeping the reaction isolated from the light at room temperature for $16 \mathrm{~h}$, reactants were precipitated with isopropyl alcohol $(50 \mathrm{~mL})$, and magnetically separated. Subsequent washing steps were needed to clean the sample, four with ethanol and five with deionized $\mathrm{H}_{2} \mathrm{O}$. Finally, the resulting solid was filtered and dried at $60^{\circ} \mathrm{C}$ for $24 \mathrm{~h}$.

Linking of fluorescent RITC to HMMSN was performed by adding under magnetic stirring a solution $(\mathrm{V}=200 \mu \mathrm{L})$ of RBITC to ethanol $(20 \mathrm{~mL})$, with concentration $(2.5 \mathrm{mg} / \mathrm{mL})$, and kept in a flask in an ice bath under $\mathrm{N}_{2}$ atmosphere for $30 \mathrm{~min}$. Afterwards, $100 \mathrm{mg}$ of HMMSN dispersed in $15 \mathrm{~mL}$ of ethanol was dropped into the RBITC solution, and kept for $24 \mathrm{~h}$ under $\mathrm{N}_{2}$ atmosphere, glycerol reflux at $2{ }^{\circ} \mathrm{C}$, and protected from light. After the reaction was completed, the fluorescent material was magnetically separated and washed first with a mixture of IPA/acetone and finally with distilled water by sonication and centrifugation. The sample was dried at $60{ }^{\circ} \mathrm{C}$ for $5 \mathrm{~h}$ and then by a desiccator. 


\subsection{Physicochemical Characterization}

\subsubsection{XRD-Structural Characterization}

Crystalline phases of the HMMSN hybrid magnetic mesoporous nanorods (HMMSN) were characterized by X-ray powder diffraction (XRD) using a Philips PW1710 diffractometer $(\mathrm{Cu} \mathrm{K} \alpha$ radiation source, $\lambda=1.54186 \AA$ ) with $2 \theta$ measurements between $10-80^{\circ}$ and scanning steps of $0.02^{\circ}$ and $10 \mathrm{~s} /$ step, on powdered samples. Low-angle X-ray diffraction (XRD) patterns of the inner channels' structure of the mesoporous silica nanorods were recorded on a PANalytical X'Pert Powder Empyrean, which was used to analyze the rodlike mesoporous SBA- 15 silica structure, using a $2 \theta$ in the range of $0.25-6^{\circ}$, and a step size of $0.01^{\circ}(5 \mathrm{~s} / \mathrm{step})$.

\subsubsection{Microscopy Morphological Characterization}

Transmission electron microscopy (TEM) images were collected on a JEOL JEM-1011 microscope (Peabody, Peabody, MA, USA, 100 kV). Sample morphology was characterized by scanning electron microscopy (SEM), using a Zeiss FE-SEM ULTRA Plus microscope (Carl Zeiss AG, Oberkochen, Germany) operated at $5 \mathrm{kV}$. The optical properties of the nanorods were measured using a fluorescent spectrophotometer (Varian Cary Eclipse, Agilent, Santa Clara, CA, USA).

Fluorescent nanoparticles imaging was performed with a fluorescence confocal multispectral imaging confocal laser microscope, Leica TCS SP8 SMD. TECHNICAL SPECIFICATIONS: Resolution: $1024 \times 1024$; scan direction X: Bidirectionnal; objetive: HC PL APO CS 63 × /1.40 OIL; and laser line: $552 \mathrm{~nm}$

Cells micrographs were imaged in a Leica DMI 6000 B microscope with the software, LAS AF 1.0.0 (Leica Microsystems, Wetzlar, Germany).

\subsubsection{Surface Chemistry Characterization}

Fourier transform infrared (FTIR) spectra of the surface functional groups of the nanorods were recorded with a Thermo Nicolet Nexus spectrometer (Nicolet, Hirsemarken, Denmark) using the attenuated total reflectance (ATR) method. The silicon chemical environments were determined by ${ }^{29} \mathrm{Si}$ solid-state magic-angle spinning nuclear magnetic resonance (MAS NMR). The NMR spectra were obtained on a Bruker Advance 400 with a spectral width of $32 \mathrm{kHz}$. A 4.0-mm rotor was used. The MAS speed was $5 \mathrm{kHz} .{ }^{29} \mathrm{Si}$ MAS NMR spectra were referenced to tetramethyl silane (TMS).

\subsubsection{Compositional Characterization}

The composition of the samples was analyzed by elemental microanalysis (CHNS) in a LECO CHNS-932 thermoanalyzer (St. Joseph, MI, USA).

\subsubsection{Textural Characterization}

Nitrogen sorption experiments were performed at $77 \mathrm{~K}$ using a Quantachrome Autosorb IQ2 (Boynton Beach, FL, USA) and the specific surface areas were estimated from the Brunauer-Emmett-Teller (BET) method. The pore size distributions were calculated from the desorption branch of the isotherms by means of the Barrett-Joyner-Halenda (BJH) method.

\subsubsection{Magnetic Characterization}

Magnetization was measured on dried HMMSN samples, with a vibrating sample magnetometer (VSM) at room temperature and applied magnetic fields from -10 to $+10 \mathrm{kOe}$.

Magnetic resonance imaging was performed with a $9.4 \mathrm{~T}$ horizontal bore magnet (Bruker BioSpin, Ettlingen, Germany) with $440 \mathrm{mT} / \mathrm{m}$ gradients and a combination of a linear birdcage resonator $(7 \mathrm{~cm}$ in diameter) for signal transmission and a $2 \times 2$ surface coil array for signal detection. A quadrature 
volume coil (7 $\mathrm{cm}$ in diameter) was also used in phantom studies. MRI post-processing was performed using ImageJ software (W. Rasband, NIH, Bethesda, MD, USA).

Relaxivity of the HMMSN samples was measured in Agar phantoms loaded with D-HMMSN nanorods, which were prepared following a previous protocol with different Fe concentrations: $0.2,0.1$, $0.05,0.02,0.01$, and $0.005 \mathrm{mM}$. T2-weighted images were acquired using a multi-slice multi-spin-echo sequence (MSME) with a $10.44 \mathrm{~ms}$ echo time, 3 s repetition time, 16 echoes with $10.4 \mathrm{~ms}$ echo spacing, $50 \mathrm{KHz}$ spectral bandwidth, flip angle $(\mathrm{FA})=110^{\circ}, 14$ slices of $1 \mathrm{~mm}, 1$ average, field of view (FOV) of $75 \times 75 \mathrm{~mm}^{2}$ (with saturation bands to suppress the signal outside this FOV), a matrix size of $256 \times 256$ (in-plane resolution of $293 \mu \mathrm{m} \mathrm{pixel}^{-1} \times 293 \mu \mathrm{m} \mathrm{pixel}^{-1}$ ), and implemented without the fat suppression option. T2*-weighted images were acquired using a multi gradient echo (MGE) sequence with a $4.44 \mathrm{~ms}$ echo time, $1.8 \mathrm{~s}$ repetition time, 16 echoes with $6.75 \mathrm{~ms}$ echo spacing, $100 \mathrm{KHz}$ spectral bandwidth, $\mathrm{FA}=30^{\circ}, 14$ slices of $1 \mathrm{~mm}, 2$ averages, and the same geometry parameters as that of the T2-weighted images.

\subsection{Biological Characterization}

\subsubsection{In Vivo Magnetic Resonance Imaging}

In vivo imaging of the HMMSN nanorods after the intraparenquimal injection was performed obtaining T2-weighted images by using an RARE-VTR sequence with the following acquisition parameters: Echo time $=9.5 \mathrm{~ms}, 8$ echos, rare factor $=2$, repetition time $=3 \mathrm{~s}$, number of averages $=2$, field-of view $=19.2 \times 19.2 \mathrm{~mm}^{2}$, image matrix $=192 \times 192$ (isotropic in-plane resolution of $100 \mu \mathrm{m} /$ pixel $\times 100 \mu \mathrm{m} /$ pixel), and 18 consecutive slices of a $0.5 \mathrm{~mm}$ thickness. T2*-weighted images were acquired using an MGE sequence with 8 echos, first echo time $=3.13 \mathrm{~ms}$, echo spacing $=3.38 \mathrm{~ms}$, repetition time $=1.4 \mathrm{~s}$, number of averages $=2$, and the same geometry parameters as that of the T2-weighted images. In order to evaluate possible ischemic lesions in the head of the animals after intravenous and intra-arterial injection, T2-weighted images were acquired using an MSME sequence with a 9 ms echo time, 3 s repetition time, 16 echoes with $9 \mathrm{~ms}$ echo spacing, $\mathrm{FA}=180^{\circ}, 2$ averages, $75 \mathrm{KHz}$ spectral bandwidth, 14 slices of $1 \mathrm{~mm}, 19.2 \times 19.2 \mathrm{~mm}^{2}$ FOV (with saturation bands to suppress the signal outside this FOV), a matrix size of $192 \times 192$ (isotropic in-plane resolution of $100 \mu \mathrm{m} /$ pixel $\times 100 \mu \mathrm{m} /$ pixel), and implemented without the fat suppression option.

\subsubsection{In Vitro Cell Mortality}

Microvasculature brain endothelial cells (ATCC CRL-2299 Bend.3 cells) in passages between 2 and 5 were used to evaluate the in vitro toxicity of the HMMSN nanorods. Cells were cultured in DMEM with $10 \%(v / v)$ of fetal bovine serum and $0,1 \%(v / v)$ of penicillin-streptomicin in a 24 wells plate with a $1.9 \mathrm{~cm}^{2}$ cell growing area (Corning, Corning, NY, USA), and incubated at $37{ }^{\circ} \mathrm{C}$ under a humidified atmosphere containing $95 \%$ air and $5 \%$ of $\mathrm{CO}_{2}$. Media were replaced every 3 days until $80 \%$ of confluence was reached. A total of four different amounts of nanoparticles were added to each plate well ( $\mathrm{N}=8$ well/group), 200, 100, 50, and $25 \mu \mathrm{g}$, and incubated for $24 \mathrm{~h}$; then, the culture was washed 3 times with PBS pH 7.4 to remove non-bound/-uptaken particles. Cells were cultured with normal media for an additional period of $12 \mathrm{~h}$. Once concluded, $200 \mu \mathrm{L}$ of media per well were collected to perform an LDH toxicity assay. (Thermo Fisher Scientific ref\# 88953). A positive control for cell death was used to determine the $100 \%$ of mortality and LDH release by adding the lysis buffer provided by the kit, while another group with only cells was used as a control for normal growth and viability.

\subsubsection{Prussian Blue Stain and Imaging}

Cells previously incubated with the HMMSN nanorods were gently washed with PBS, permeabilized for $1 \mathrm{~h}$ with PBS and $0.01 \%(v / v)$ Tween 20, and fixed with $4 \%(v / v)$ of methanol free PFA. Later, the culture was washed and covered with Prussian Blue working solution composed by an aqueous solutions mixture (1:1) of $\mathrm{HCl}$ at $20 \%(w / v)$ and potassium hexacyanoferrate (II) 
trihydrate at 10\% $(w / v)$. After $30 \mathrm{~min}$, cells were washed with PBS and imaged. Microphotographs at $10 \times, 20 \times$, and $40 \times$ were randomly taken from samples using a phase contrast filter.

\subsubsection{In Vivo Experimental Groups}

All animal studies were conducted with Male Sprague-Dawley rats of 325-350 g. To assess the contrast in normal brain tissue, an intraparenchymal injection of the HMMSN nanorods $\left(0.41 \mathrm{mg} \mathrm{mL}^{-1}\right)$ was performed $(\mathrm{N}=2)$. Rats were placed in a stereotaxic frame (Stoelting Co., Wood Dale, IL, USA) under sevoflurane anesthesia. A 1-cm-long midline incision was made in the scalp, beginning midway between the eyes and terminating behind the lambda. A cotton swab was used to clear away the soft tissue covering the skull. A Hamilton syringe (Hamilton; $10 \mu \mathrm{L}$ ) was filled with the nanorods suspension $\left(0.41 \mathrm{mg} \mathrm{mL}^{-1}\right)$ dissolved in saline. The syringe was mounted onto the injection pump and the needle was positioned directly over the bregma. The $\mathrm{x}, \mathrm{y}$, and $\mathrm{z}$ axis coordinates were all set to zero. The needle was then positioned at the entry point, $+0.6 \mathrm{~mm}$ anterior and $-2.9 \mathrm{~mm}$ lateral of the bregma to the right. A small cranial burr hole was drilled through the skull at the entry point. The needle was slowly inserted into the basal ganglia to a depth of $5.5 \mathrm{~mm}$ below the surface of the skull, and a volume of $10 \mu \mathrm{L}$ of HMMSN was injected at a rate of $1 \mu \mathrm{L} \mathrm{min}{ }^{-1}$ over $10 \mathrm{~min}$. The needle was left in place for $10 \mathrm{~min}$ and then removed at a rate of $1 \mathrm{~mm} / \mathrm{min}$ to prevent reflux of the injected solution. The same procedure was performed in the left hemisphere, injecting $10 \mu \mathrm{L}$ of saline. The burr hole was filled with bone wax (Ethicon, Somerville, NJ, USA), and the scalp incision was closed. The rats were placed in an animal box after surgery for recovery in a warm place with access to food.

Total signal intensity was calculated by normalizing the intensity of each injection zone (for saline or HMMSN nanorods solutions) to a physiological tissue intensity area. With the aim to evaluate the potential toxicity effect of the nanorods regarding the administration route, two additional groups were added: Intravenous and intra-arterial route $(\mathrm{N}=3$ /group). For the intravenous administration, $1 \mathrm{~mL}$ of HMMNS nanorods $\left(0.41 \mathrm{mg} \mathrm{mL}^{-1}\right)$ were gently injected through the right jugular vein of the animal previously exposed with a short incision on the right side of the animal neck. To perform the intra-arterial administration, a small incision was made in the neck of the animal, the muscles were separated to access the common right carotid artery, and the bifurcation area of the external and internal carotid artery. Then, a permanent suture knot was carried out in the right external carotid and pterygopalatine artery, while in the common and internal carotid artery, a transient knot was performed, creating a region with no blood flow to avoid bleeding during manipulation. An incision was made in the external carotid to insert a cannula attached to a syringe containing the HMMNS nanorods suspension. The transient knots of the common and internal carotid were then released, restoring the ascending flow to the brain. The upward flow was maintained for $10 \mathrm{~min}$ to stabilize the animal and later, $450 \mu \mathrm{L}$ was injected for $20 \mathrm{~min}$ to avoid volume overload adverse effects due to the increase in blood volume. Once the administration was completed, the cannula was removed, and the external carotid was closed with a permanent knot, the incision in the neck was sutured, and the anesthetized animal was awakened for recovery.

Blood extraction and analysis: A total volume of $1 \mathrm{~mL}$ of blood was extracted from the tail vein of the animals and collected in tubes with heparin (BD Vacutainer ${ }^{\circledR}$ Heparin Blood Collection Tubes). The analysis was conducted with a Reflotron ${ }^{\circledR}$ plus (Roche, Basel, Switzerland) by adding $33 \mu \mathrm{L}$ of the blood sample to reactive strips for Glutamate Oxaloacetate Transaminase enzyme GOT (ref: 10745120202 Roche), Glutamate Pyruvate Transaminase enzyme GPT (ref: 10745138202 Roche), and Creatinine (ref: 10886874202 Roche).

\section{Results and Discussion}

\subsection{Physicochemical Properties}

SBA-15 mesoporous silica nanorods (S15N) were obtained under strongly acidic conditions from the condensation of hydrolyzed silica precursors in the presence of a soft template composed by a 
mixture of Pluronic P123, a triblock copolymer surfactant, and glycerol, as previously reported [32]. Afterwards, magnetic functionality was added by covalently anchoring [33] magnetite nanoparticles to the S15N surface by coating all with an aminated silica grafting (Figure 1) while the optical response was achieved by linking a dense fluorescent moiety layer (rhodamine B isothiocyanate) to the surface amines of the HMMSN sample.

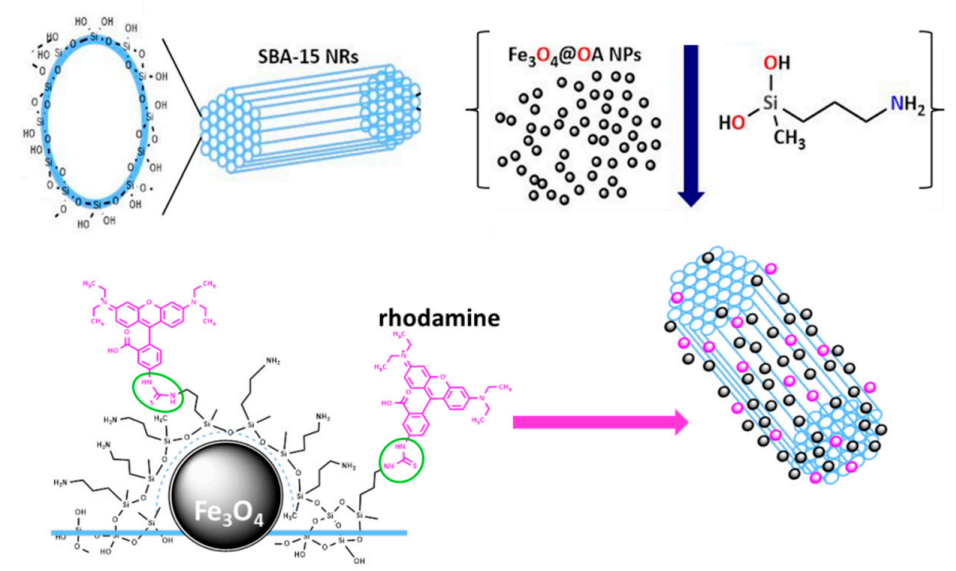

Figure 1. Scheme of the ordered mesoporous silica ceramic with $\mathrm{Si-OH}$ groups exposed on the surface (top). Anchoring of magnetite nanoparticles by adding functional ethoxysilane molecules allows the formation of the HMMSN hybrid mesoporous magnetic nanorods. Fluorescent dye (rhodamine) is further attached on top.

Structural properties were analyzed by X-ray diffraction at a low angle and wide angle to asses both the small scale order of the mesoporous silica channels and the medium scale order structures, like the magnetite nanoparticles, respectively. Low angle X-ray diffraction patterns of S15N and HMMSN samples, in Figure 2A, show the Bragg diffraction maxima at (100), (110), and (200) planes, corresponding to a highly ordered 2D hexagonal structure (space group P6m), which is characteristic of mesoporous nanostructures [14]. From the position of the (100) diffraction peaks, the unit cell parameters $\left(\mathrm{a}_{0}\right)$ for the $\mathrm{S} 15 \mathrm{~N}$ and the hybrid HMMSN nanostructures were calculated and are shown in Table 1. In addition, Figure 2B shows the X-ray diffraction pattern at a wide angle range of the hybrid nanostructure HMMSN. The position and relative intensities of crystalline magnetite $\left(\mathrm{Fe}_{3} \mathrm{O}_{4}\right)$ (inverse spinel structure (JCPDS 19-0629)) allow us to assume that magnetite NPs are attached to the mesoporous silica nanostructures whose amorphous phase is observed as a broad band at the $22-23^{\circ}$ $2 \theta$ range.
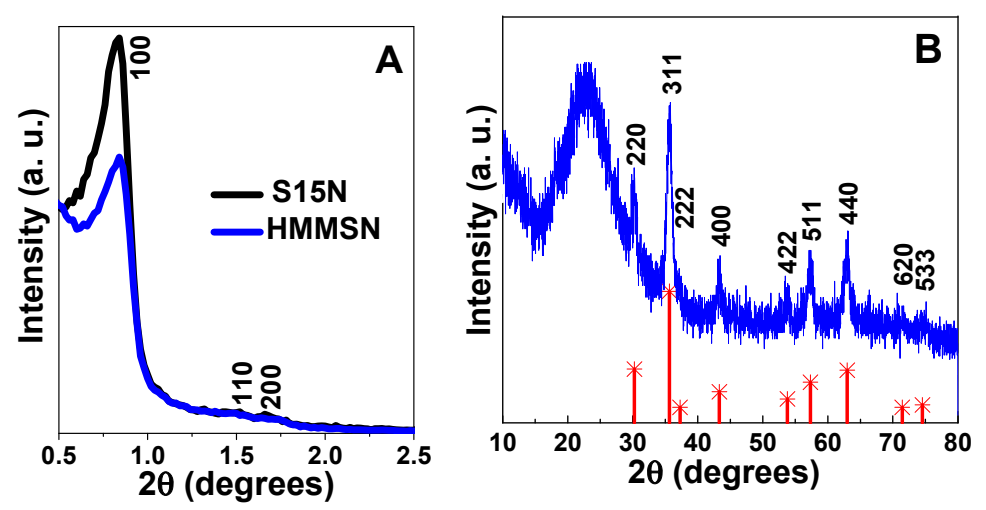

Figure 2. (A) Low-angle XRD patterns of the S15N mesoporous silica and HMMSN hybrid magnetic mesoporous nanorods and (B) the XRD pattern of HMMSN hybrid magnetic mesoporous nanorods (blue), with the theoretical XRD pattern of magnetite (red) for comparison purposes. 
Chemical topology was studied by FITR spectroscopy, which allows an analysis of the vibration bands of the functional groups present at the surface of the samples. In Figure 3, FTIR spectra of mesoporous nanorods, S15N, and their magnetic counterparts, HMMSN, are presented for comparison purposes. In first place, the appearance of a stretching broad band at 1050-1025 $\mathrm{cm}^{-1}$ $v(\mathrm{Si}-\mathrm{O}-\mathrm{Si})$ and the bending band at $840-780 \mathrm{~cm}^{-1}$ indicates the formation of the siloxane matrix. Around $970-940 \mathrm{~cm}^{-1}, v(\mathrm{Si}-\mathrm{OH})$, the free silanol vibration band of the $\mathrm{S} 15 \mathrm{~N}$ mesoporous silica, is present, which partially disappears in the case of the HMMSN nanorods. The overlapping with the siloxane broad band is due to a decrease in the amount of available silanol groups present in the functionalized magnetic material. This result is consistent with the formation of a bifunctionalized silanol grafting that may have been anchored to the S15N external surface by condensation of their free silanol groups with dialkoxysilane molecules during the magnetite nanoparticles' attachment process. In addition, broadened medium bands, between 3400-3100 cm $\mathrm{cm}^{-1}$ and 3550-3200 cm $\mathrm{cm}^{-1}$, are observed, which correspond to the $\mathrm{N}-\mathrm{H}$ and $\mathrm{O}-\mathrm{H}$ bonds, respectively. The characteristic $\mathrm{C}-\mathrm{H}$ vibration bands of the stretching $v(\mathrm{C}-\mathrm{H})$ and bending $\delta\left(\mathrm{CH}_{3}\right)$ of the methyl groups are shown at approximately $2900-3000 \mathrm{~cm}^{-1}$ and at $1480 \mathrm{~cm}^{-1}$, respectively. Finally, the weak peaks at $1630 \mathrm{~cm}^{-1}, 1580 \mathrm{~cm}^{-1}$, and $1325 \mathrm{~cm}^{-1}$ correspond to the adsorption of water molecules in the material surface $\delta(\mathrm{H}-\mathrm{OH})$, the scissoring vibration of the $\mathrm{N}-\mathrm{H}$ bond, and the stretching vibration of the $\mathrm{C}-\mathrm{N}$ bond, respectively.

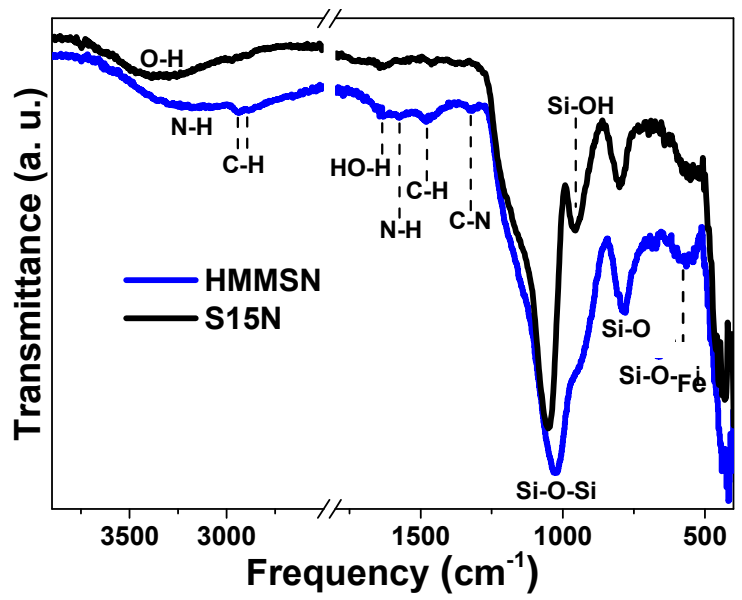

Figure 3. FTIR spectra of the S15N mesoporous silica matrix and HMMSN hybrid magnetic mesoporous nanorods.

Moreover, HMMSN nanorods were analyzed by elemental chemical analysis (ECA) to determine the nitrogen content present in the sample. The experimental weight percentage of functionalization was calculated assuming that all nitrogen found in the sample proceeded from the hydrolysed 3-aminopropyl-methyl-diethoxysilane molecules, which was used to trap the magnetite NPs onto the external S15N surface by the formation of a graft (Figure 1). Considering this, the so obtained weight percentage, $22.5 \%$, confirms that the surface was successfully modified by a large number of organic molecules. In addition, this value highlights the efficiency of the synthetic single step double procedure: Anchoring magnetite NPs and functionalizing the surface at the same time.

The fluorescent properties of the rhodamine coated nanorods were studied by means of fluorescence spectrometry and confocal microscopy. Figure 4A presents the photoluminescence spectra of the rhodamine functionalized HMMSN nanorods, showing that the excitation has a maximum located at $\lambda^{\max } e_{\mathrm{ex}}=560 \mathrm{~nm}$, for which a maximum emission peak is observed at $\lambda^{\mathrm{exc}} \mathrm{em}=580 \mathrm{~nm}$ in concordance with the fluorescence excitation/emission pattern of rhodamine $\left(\lambda_{\mathrm{ex}}=543 \mathrm{~nm}\right.$ and $\lambda_{\mathrm{em}}=580 \mathrm{~nm}$ ). Fluorescent confocal micrographs under a single $552 \mathrm{~nm}$ laser excitation are shown in Figure 4B, where the intense red color emission spots, corresponding to the fluorescent HMMSN nanorods, are depicted as being evenly distributed. This optical functionality added to the silica 
surface without modifying the structural, textural, or physical properties endows the nanorods with additional fluorescent tagging for biological imaging.
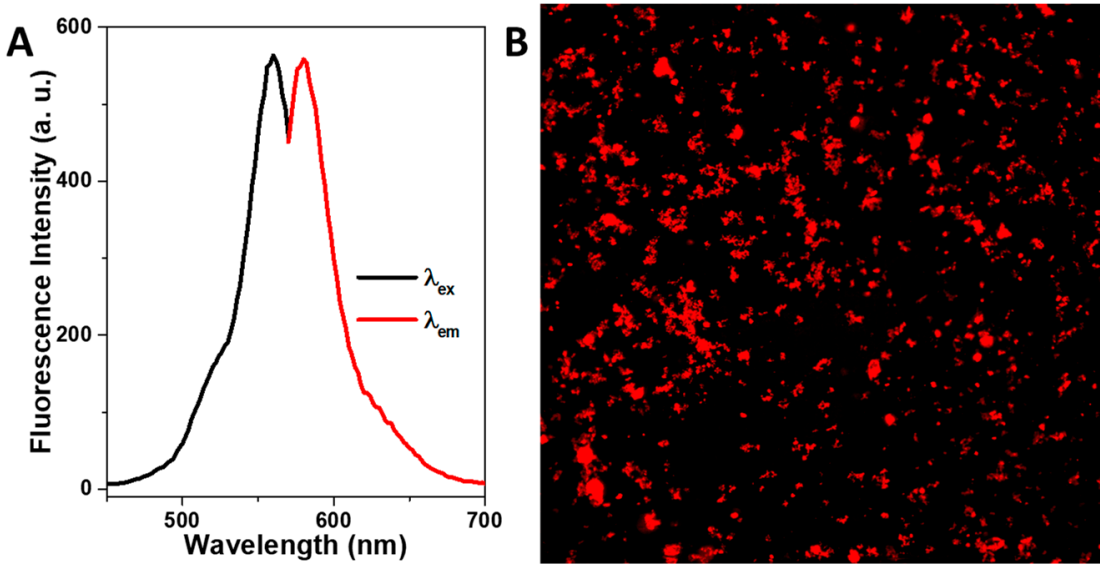

Figure 4. (A) Photoluminescence spectra and (B) confocal fluorescence images of HMMSN hybrid magnetic mesoporous nanorods.

The textural properties of S15N and HMMSN were assessed by performing $\mathrm{N}_{2}$ adsorption isotherms as can be observed in Figure 5A, which shows a characteristic type-IV isotherm of SBA-15 mesoporous materials with an ordered cylindrical pore arrangement with open ends. Both curves show a characteristic H1-type hysteresis cycle [34] (parallel adsorption and desorption branches) with different areas. The smaller HMMSN area corresponds to the partial clogging of the pores by the magnetite NPs, which reduce the availability of channels.
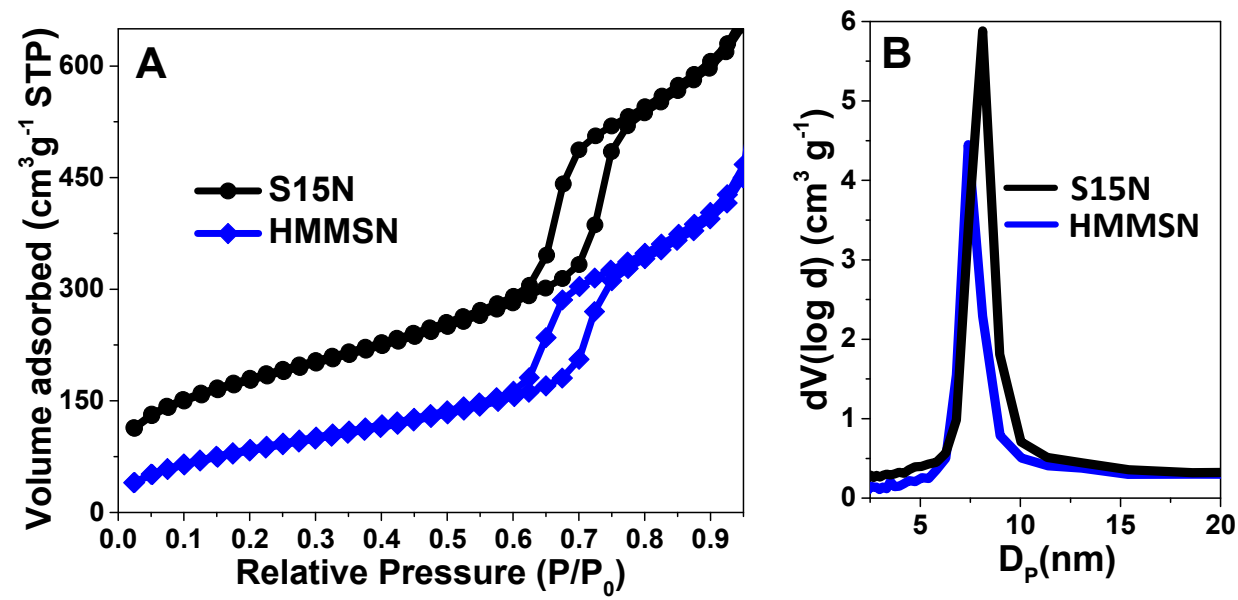

Figure 5. (A) $\mathrm{N}_{2}$ sorption isotherms and (B) pore size distribution of the SBA-15 matrix and HMMSN hybrid magnetic mesoporous nanorods obtained from the BJH method.

The textural properties (pore size distribution and specific surface area) were estimated from the $\mathrm{N}_{2}$ adsorption isotherms and are plotted in Figure 5B. It is evident that the HMMSN hybrid nanorods present a similar pore size (around $9 \mathrm{~nm}$ ) and a narrower pore size distribution than the precursor mesoporous matrix. This result highlights the efficiency of the present functionalization procedure, which, besides alternative routes that block the pores [35,36], it is also able to provide a large degree of surface modification while preserving the textural properties of native S15N. In Table 1, a comparison of the textural properties between native S15N and hybrid HMMSN is shown for both materials, including a large specific surface area, which endows them with a high capacity for loading moieties of therapeutic interest. 
Table 1. Textural and structural values of the SBA-15 matrix and HMMSN hybrid magnetic nanocomposite. Surface area $\left(S_{\mathrm{BET}}\right)$, total pore volume $\left(\mathrm{V}_{\mathrm{p}}\right)$, pore diameter $\left(\mathrm{D}_{\mathrm{BJH}}\right)$, unit cell parameter $\left(\mathrm{a}_{0}\right)$, thickness of the mesopores walls $\left(\mathrm{t}_{\mathrm{wall}}=\mathrm{a}_{0}-\mathrm{D}_{\mathrm{BJH}}\right)$, and iron oxide weight percentage $\left(\mathrm{W}_{\mathrm{mag}}\right)$, expressed as $\mathrm{Fe}_{3} \mathrm{O}_{4}$, determined by flame atomic absorption spectroscopy, FAAS.

\begin{tabular}{cccccccc}
\hline Samples & $\mathbf{S}_{\text {BET }}\left(\mathbf{m}^{\mathbf{2}} \mathbf{g}^{-\mathbf{1}}\right)$ & $\mathbf{V}_{\mathbf{p}}\left(\mathbf{c m}^{\mathbf{3}} \mathbf{g}^{-\mathbf{1}}\right)$ & $\mathbf{D}_{\text {BJH }}(\mathbf{n m})$ & $\mathbf{d}_{\mathbf{1 0}}(\mathbf{n m})$ & $\mathbf{a}_{\mathbf{0}}(\mathbf{n m})$ & $\mathbf{t}_{\text {wall }}(\mathbf{n m})$ & $\mathbf{W}_{\text {mag }}(\%)$ \\
\hline S15N & 617.10 & 1.78 & 8.18 & 10.52 & 12.15 & 4.03 & 0.00 \\
HMMSN & 318.97 & 1.82 & 7.40 & 10.51 & 12.14 & 4.77 & 7.60 \\
\hline
\end{tabular}

The morphology of native S15N and hybrid HMMSN nanorods was studied with the help of transmission and scanning electron microscopy. In Figure 6, SEM and TEM images, on the top and bottom, respectively, can be observed for S15N mesoporous silica on the left, and hybrid HMMSN nanorods on the center and right in different locations and with different magnifications. TEM images of the S15N matrix reveal a hexagonal structure with a cylindrical ordered pore disposition with a diameter estimated from the images to be $8.5 \mathrm{~nm}$, in good agreement with the value estimated by the BJH method of $8.177 \mathrm{~nm}$. On the other hand, the SEM images show that the S15N matrix is mainly composed of small particles with a uniform rod morphology. In addition, the presence of magnetite nanoparticles anchored on the $\mathrm{S} 15 \mathrm{~N}$ ceramic surface can be clearly identified for the HMMSN nanorods, showing a well-defined mesoporous structure with NPs homogeneously distributed around it. The average pore diameter estimated from these micrographs was $9.1 \mathrm{~nm}$, higher than the value estimated from the $\mathrm{BJH}$ method of $7.40 \mathrm{~nm}$, which means that the anchoring procedure may have slightly distorted the ordered structure of the mesoporous silica, as has already been observed before [33]. This increase in pore diameter partly explains the observed increase in the pore volume.
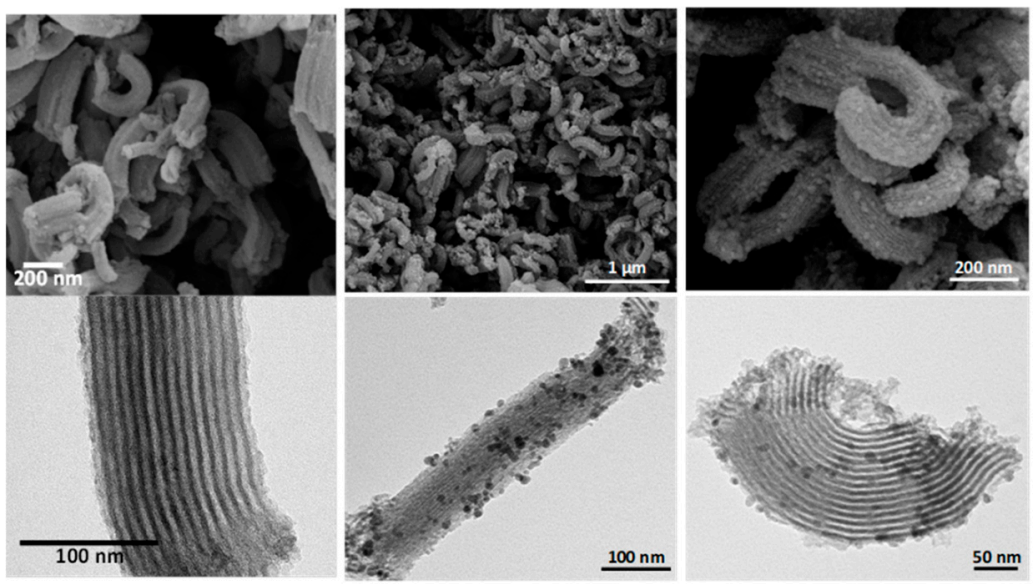

Figure 6. SEM (top) and TEM (bottom) micrographs of (left) S15N mesoporous silica and (center and right) HMMSN hybrid magnetic mesoporous nanorods in different locations and with different magnifications.

The size distribution statistics of these rodlike particles (Figure 7) display an average width of $92 \pm 25 \mathrm{~nm}$, and a length in the range between 300 and $540 \mathrm{~nm}$, similar to those found by Johansson [37]. Rod-like morphology can be tailored by controlling the acid mixture $\left(\mathrm{HCl} / \mathrm{H}_{3} \mathrm{PO}_{4}\right)$, which is a key factor in the production of nanorods [14].

The ${ }^{29} \mathrm{Si}$ solid-state MAS NMR spectrum shows the identified signals corresponding to different $\mathrm{Q}^{\mathrm{n}}$ and $\mathrm{D}^{\mathrm{n}}$ silicon species [38] present in the HMMSN material associated with the relative amounts of silica frameworks and their corresponding functionalization. 
Figure 8 shows the ${ }^{29} \mathrm{Si}$ solid-state MAS NMR spectrum of the HMMSN sample. The most representative chemical shifts for the local silicon environments in the HMMSN nanorods are $\mathrm{D}^{1}$ $(\delta=-20.51 \mathrm{ppm}), \mathrm{D}^{2}(\delta=-26.99 \mathrm{ppm}), \mathrm{D}^{2}(\delta=-31.40 \mathrm{ppm})$, and $\mathrm{Q}^{4}(\delta=-114.24 \mathrm{ppm})$. The main difference observed in Table 2 is related to the number of oxygen atoms connected to each silicon atom, which forms the building units. Thus, the replacement of $\mathrm{O}$ atoms by aminopropyl and methyl groups caused substantial high-frequency (downfield) shifts, therefore, the chemical shifts of the siloxane centers are sensitive to neighbor effects in the chain structure, thus revealing the microstructure of the material.
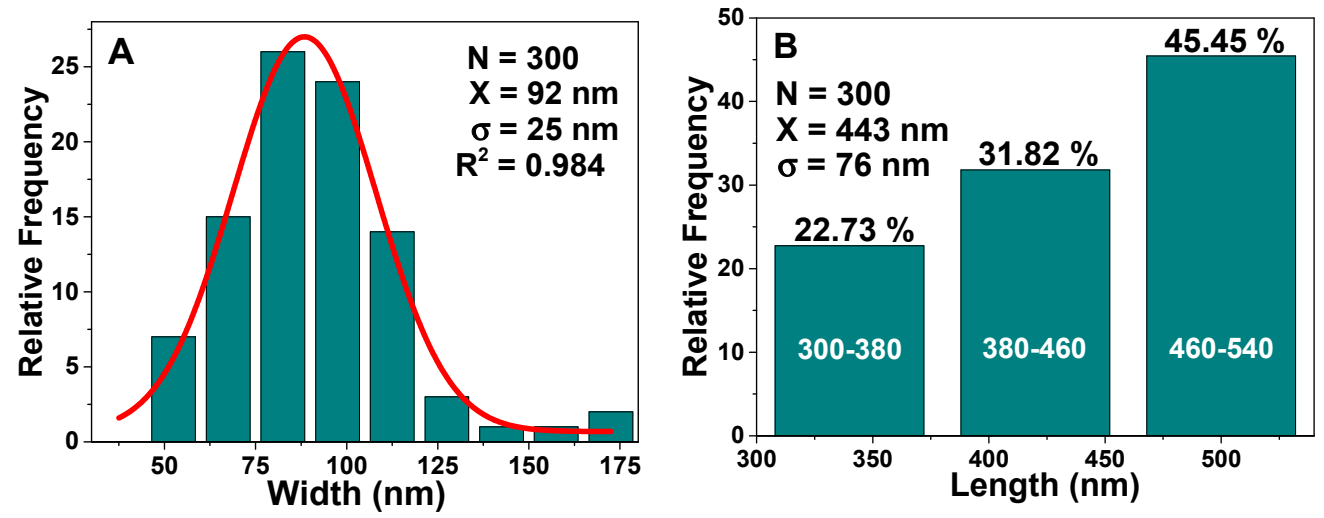

Figure 7. (A) Width and (B) length distributions of the S15N mesoporous silica nanorods. (A) N is the sampling, $\mathrm{X}$ and $\sigma$ are the center and width of the Gaussian distribution, while for (B), $\mathrm{X}$ and $\sigma$ are obtained from the arithmetic mean.
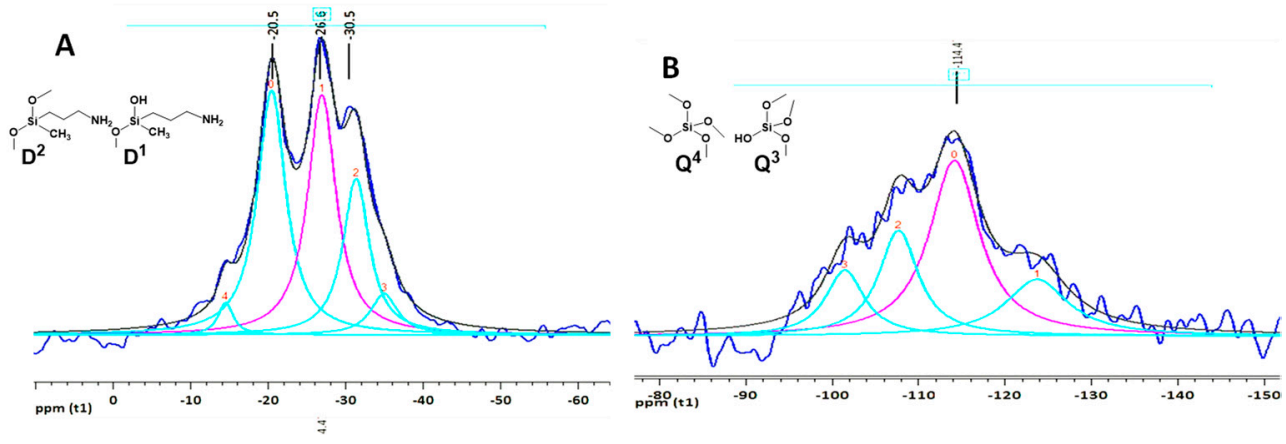

Figure 8. ${ }^{29} \mathrm{Si}$ solid-state CP-MAS NRM spectra of HMMSN hybrid magnetic mesoporous nanorods with fittings of $(\mathbf{A}) \mathrm{D}^{\mathrm{n}}$ siloxane centers and $(\mathbf{B}) \mathrm{Q}^{\mathrm{n}}$ siloxane centers.

The most intense peaks are located between -18 and $-32 \mathrm{ppm}$ are related to $\mathrm{D}^{\mathrm{n}}$ siloxane centers, coinciding with that reported by Wiench et al. [39], and thus corroborating the functionalization and anchoring of magnetite nanoparticles onto the silica surface. The results are summarized in Table 2. Additionally, the areas under the curve were quantified to approximately define the bands associated with each ${ }^{29}$ Si chemical shift of the HMMSN material. 
Table 2. Chemical shift and silicon environments of the HMMSN hybrid magnetic mesoporous nanorods.

\begin{tabular}{ccc}
\hline Chemical Shift (ppm) & Silicon Environment & Area Under a Curve (\%) \\
\hline-123.80 & $\mathrm{Q}^{4}$ & 5.26 \\
-114.24 & $\mathrm{Q}^{4}$ & 12.89 \\
-107.77 & $\mathrm{Q}^{4}+\mathrm{Q}^{3}$ & 6.12 \\
-101.55 & $\mathrm{Q}^{3}$ & 3.78 \\
-35.01 & $\mathrm{D}^{2}$ & 4.18 \\
-31.40 & $\mathrm{D}^{2}$ & 15.12 \\
-26.99 & $\mathrm{D}^{2}$ & 25.22 \\
-20.51 & $\mathrm{D}^{1}$ & 25.59 \\
-14.58 & $\mathrm{D}^{1}$ & 1.84 \\
\hline
\end{tabular}

Figure 9 shows the room temperature hysteresis loop of the functionalized nanorods as a function of the applied magnetic field (up to $10 \mathrm{kOe}$ ). The material exhibits an excellent magnetic response normalized to the magnetite mass with clear superparamagnetic (SPM) behavior. Compared to the saturation magnetization value obtained with other similar magnetic mesoporous nanostructures previously reported by our group [33] and by other research groups [40-43], this is higher and similar to some functionalized magnetite nanoparticles [44,45]. The magnetization $\mathrm{M}$ vs. magnetic field $\mathrm{H}$ cycle is slightly shifted to negative magnetic fields; that may be related to magnetostatic interactions [46] or exchange anisotropy [47] since magnetite nanoparticles are attached to the external mesoporous nanorod and thus cannot be treated as if each nanoparticle were a pure dipole.

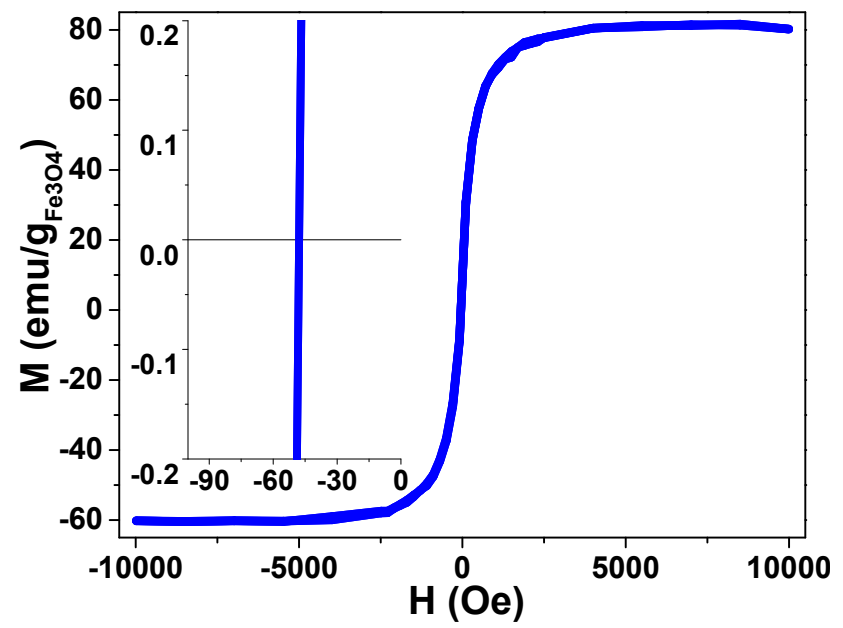

Figure 9. Magnetic hysteresis loop from 10 to $-10 \mathrm{kOe}$ of HMMSN hybrid magnetic mesoporous nanorods up to $10 \mathrm{kOe}$, measured at room temperature, and a magnification of the low field region, revealing an almost absent coercive file.

\subsection{Relaxivity and Brain MRI Contrast of the HMMSN Nanorods}

The HMMSN nanorods relaxivity was assessed by magnetic resonance, showing values of $258.94 \mathrm{mM}^{-1} \mathrm{~s}^{-1}$ and $324.68 \mathrm{mM}^{-1} \mathrm{~s}^{-1}$ for T2 and T2* sequences, respectively (Figure 10). In this sense, the iron content (Table 1) provides enough contrast for adequate imaging compared to other commercial contrast agents [48]. 

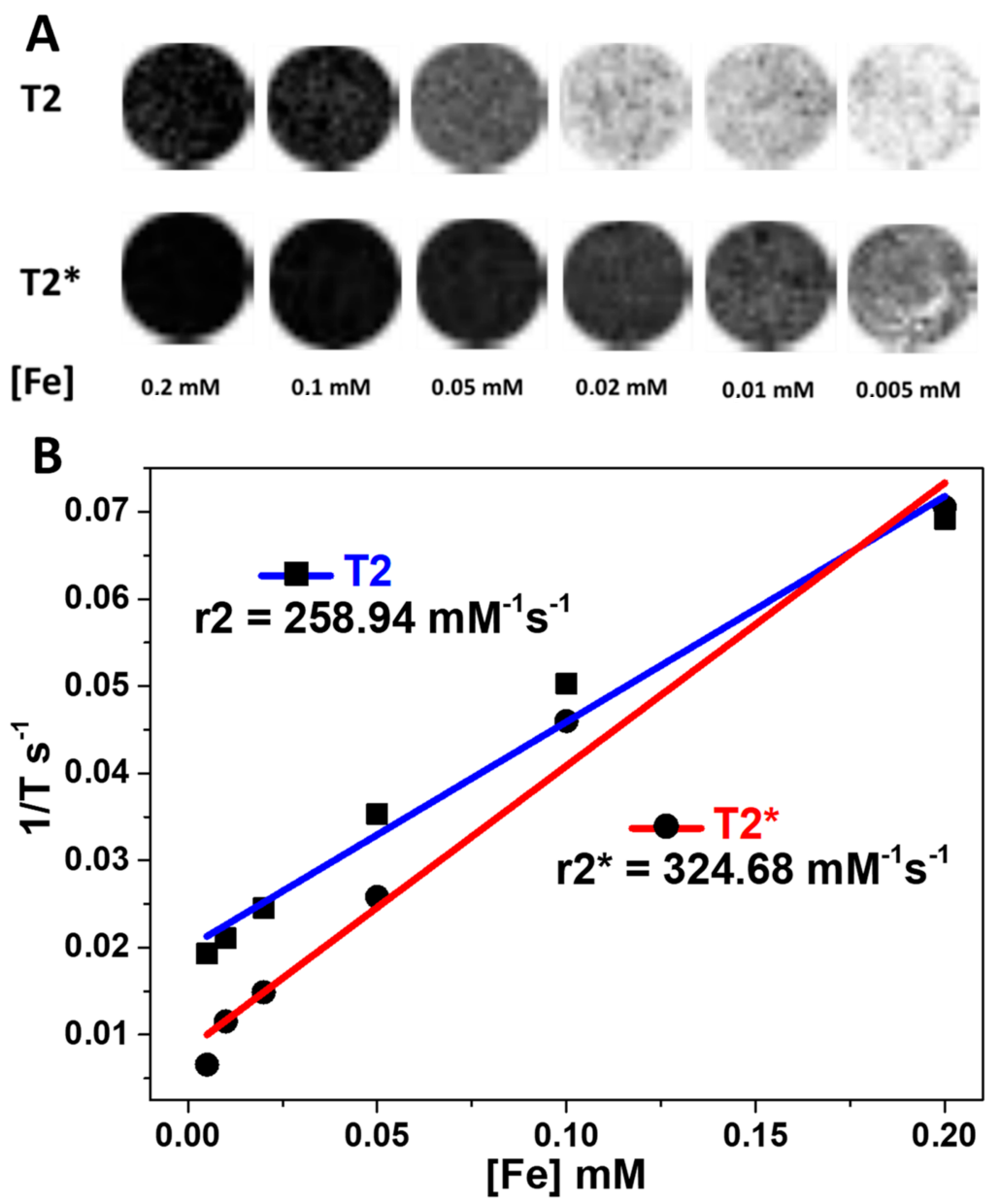

Figure 10. (A) T2 and T2* weight images of an agar phantom template, with crescent concentrations of Fe coupled to HMMSN hybrid magnetic mesoporous nanorods. (B) Relaxivity values obtained with T2 and $\mathrm{T} 2 *$ weight images.

The HMMSN nanorods suspension was injected in the right hemisphere of male Sprague-Dawley rats; and a vehicle injection of saline was performed in the left hemisphere (Figure 11A). Figure 11B shows that the T2 signal intensity in the nanoparticles injection area decreased to around $58 \%$, generating an hipointensity area with increased contrast compared to a normal tissue intensity region, while the vehicle signal intensity only decreased by $5.7 \%$. The $\mathrm{T} 2 *$ signal intensity decreased by $52 \%$ while the vehicle group only around $15 \%$. Nanoparticles concentrated in the injection spot enhance the contrast with normal brain tissue in both the $\mathrm{T} 2$ and $\mathrm{T} 2 *$ sequences. 
A

T2WI

$\mathrm{T} 2 * \mathrm{WI}$
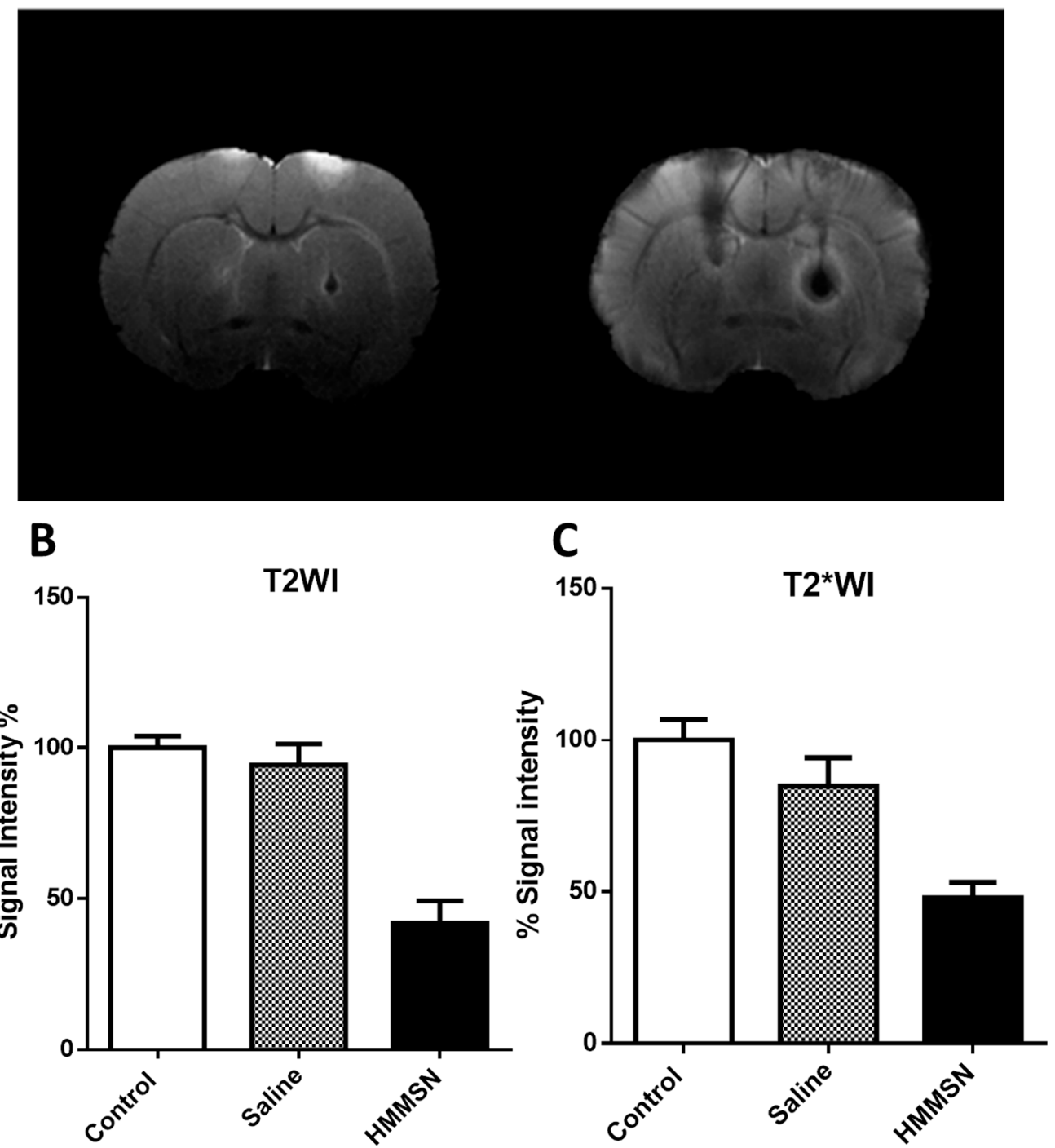

Figure 11. (A) $\mathrm{T} 2$ and $\mathrm{T} 2 *$ weight images after intraparenchymal injection of $10 \mu \mathrm{L} 0.9 \% \mathrm{NaCl}$ saline (left hemisphere) and $10 \mu \mathrm{L}$ of a suspension $(0.41 \mathrm{mg} / \mathrm{mL})$ of HMMSN hybrid magnetic mesoporous nanorods in saline (right hemisphere). (B,C) \% signal intensity is decreased in the injection area compared to the control for normal tissue intensity in $\mathrm{T} 2$ and $\mathrm{T} 2{ }^{*}$ weight images, respectively. ( $\mathrm{N}=2$ /group).

\subsection{In Vitro Cell Mortality by LDH Toxicity Assay and Prussian Blue Stain of the HMMSN Nanorods}

Nanotechnology allows the achievement of high levels of sophistication and personalization for different applications, like diagnosis, therapy, or even both. One of the biggest challenges has always been to deal with the brain; in brief, overcoming the blood brain barrier and reaching an adequate concentration of nanoparticles to produce the desired effect without causing any side damage have always been the main issues. In this regard, endothelial cells are the primary component that perform most interactions with the nanoparticles suspension after systemic administration, impairing the physiological structure of the cells, damaging the membrane, and altering the integrity and permeability of the layer $[49,50]$. According to this, it will be mandatory to assess the potential toxicity derived from different interactions of the new materials and covers involved in this process. This work is focused on possible future applications in the brain area; in this sense, brain microvasculature cells 
(Bend.3) were selected due to their strong relationship with brain permeability and their pivotal role in the neurovascular unit.

Endothelial cells were cultured with the HMMSN nanorods for $24 \mathrm{~h}$, showing a significant mortality only when the highest amount of $200 \mu \mathrm{g}$ was used. Regarding the samples with 100, 50, and $25 \mu \mathrm{g}$ amounts, they showed no significant mortality compared to the control group (Figure 12).

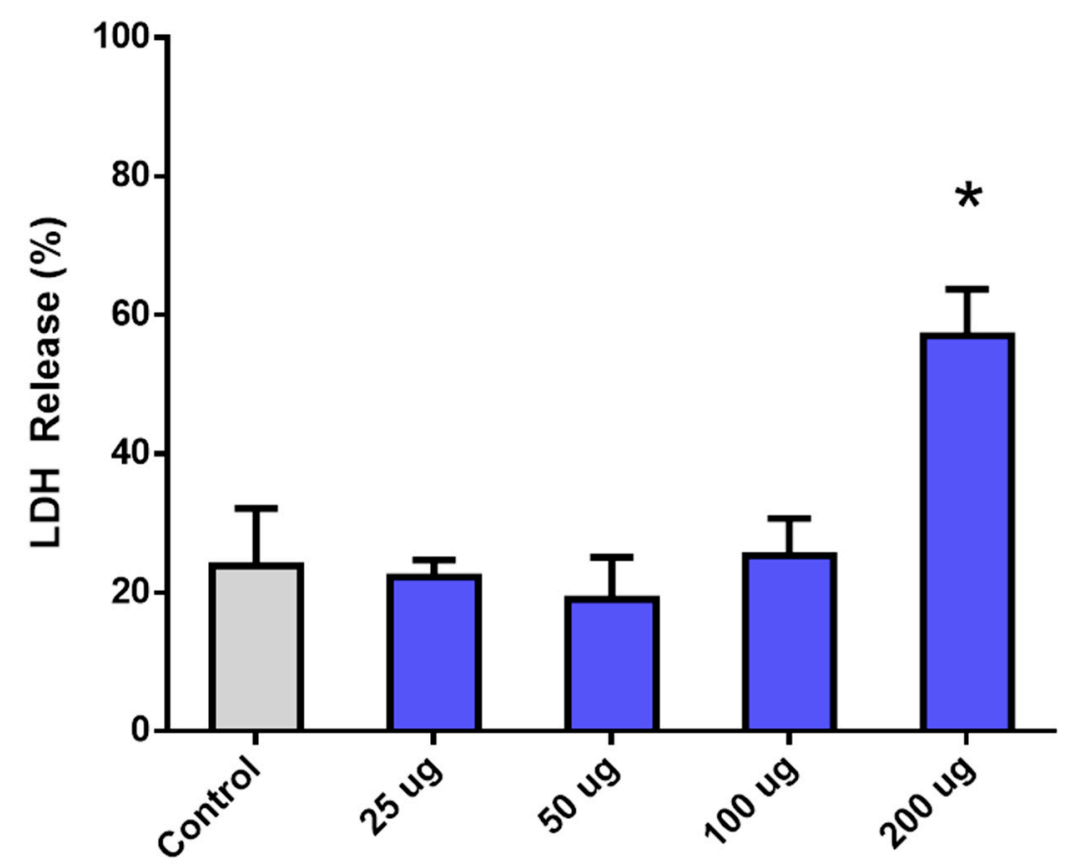

Figure 12. Cell viability assay representing the percent of LDH release of Bend.3 endothelial cells treated with increasing amounts of HMMSN hybrid magnetic mesoporous nanorods. Values are normalized to a positive control for cell death. ( $\mathrm{N}=8 /$ groups, ${ }^{*}=p<0.005$ compared to the control group).

The uptake was evaluated in a qualitative way through a Prussian Blue stain of the nanorods, as shown in the Figure 13; enough nanorods were taken up by cells to cover most of the citoplasmatic portion. This elevated uptake is probably due to the presence of amino functionalized nanorods and the surface affinity of the cells to these groups, which probably induce a strong attraction, thus increasing the binding/uptake. However, the presence of methyl and silanol groups contribute by having a negative charge in the $\mathrm{pH}$ conditions of deionized water as was corroborated by the measured $\mathrm{Z}$ potential, $-18.63 \mathrm{mV}$, which is highly convenient since cationic nanoparticles are usually associated with high toxicity as Fröhlich demonstrated [51]. In summary, only the highest concentration shows a significant toxicity due to the massive presence of NRs in the cells, which is evidence of the optimal biocompatible properties of mesoporous nanorods with brain endothelial cells. 
$10 x$

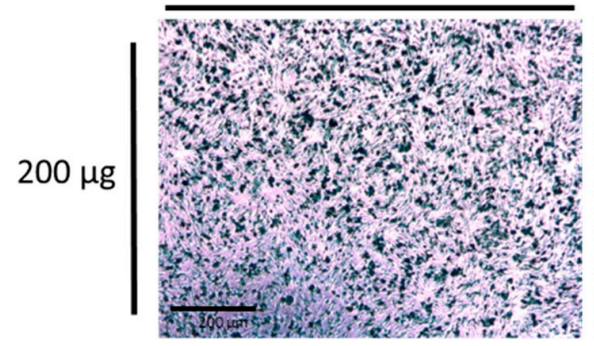

$50 \mu \mathrm{g}$
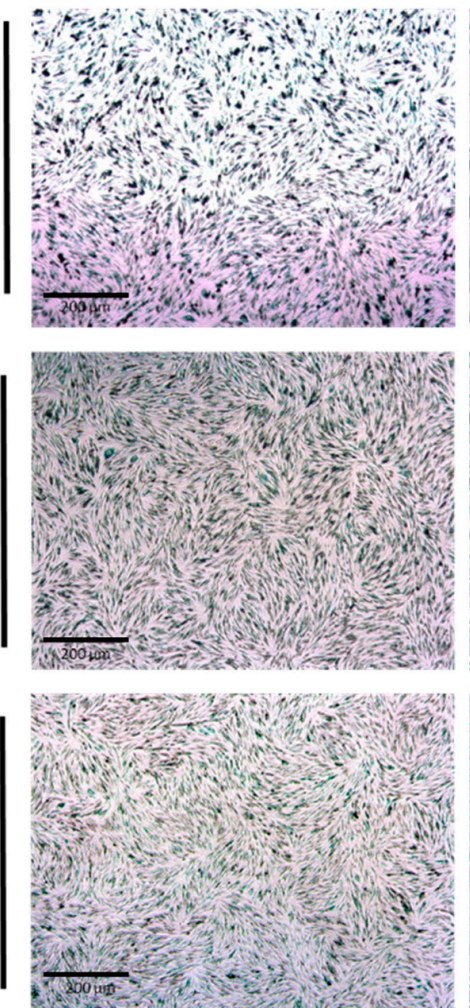

$20 x$
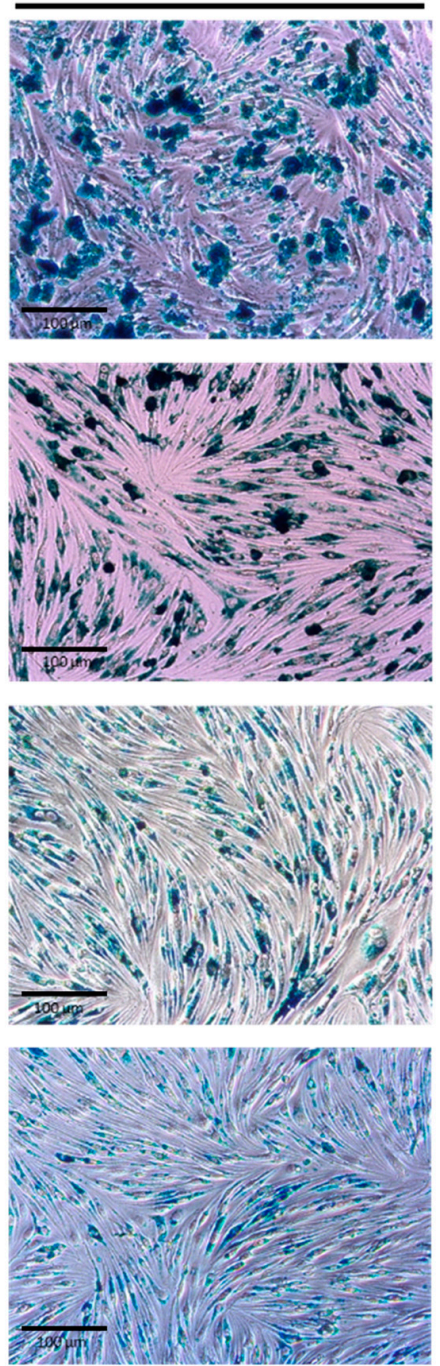

$40 x$
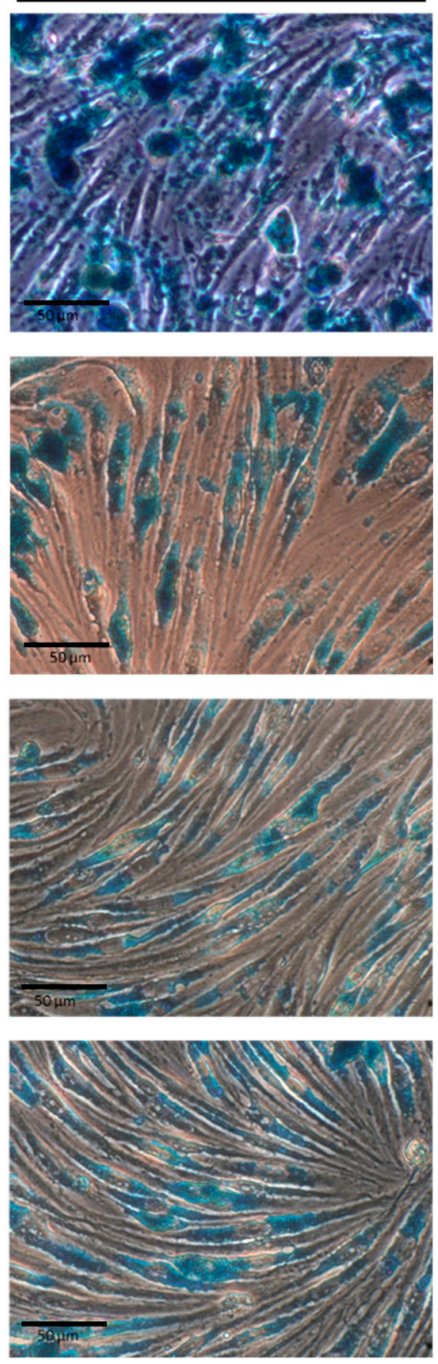

Figure 13. Prussian Blue stain of HMMSN hybrid magnetic mesoporous nanorods after $24 \mathrm{~h}$ of incubation with Bend. 3 endothelial cells. Scale bars: $10 \times=200 \mu \mathrm{m}, 20 \times=100 \mu \mathrm{m}$, and $40 \times=50 \mu \mathrm{m}$.

3.4. Brain MRI Evaluation after Intravenous and Intra-Arterial Injections and In Vivo Toxicity of the HMMSN Nanorods

Toxicity due to particle-cell interaction is not the only source of potential damage in nanoparticles treatments; in in vivo models, mechanical damage is also important as anastomosis in diverse organs reduces vessel caliber trapping of the particles, causing occlusions that could lead to ischemic lesion or could damage the integrity of the vessels' structure, leading to a possible hemorrhagic transformation. Another aspect considered in this work is the administration route. After being injected into the external carotid artery, the first tissue with which particles have contact with is the cerebral microvasculature. Due to its advantageous ascending flow, this is the optimal route to observe any effects on the cerebral area without passing through the rest of the organs with a consequent loss of nanoparticles. On the other hand, venous administration through the jugular vein, where a descending flow transports the nanoparticles to the heart and then to the rest of the body, disseminating them to different organs of the animal, allows us to evaluate their effect [52].

Based on this, a total of $1.4 \mathrm{mg} \mathrm{kg}^{-1}$ of mesoporous nanoparticles were administrated in two different groups: Venous administration group and arterial administration group. Animals were followed by MRI for 14 days to evaluate any possible associated damage in the brain. No ischemic or 
hemorrhagic damage were observed through the magnetic resonance images in any group (Figure 14), and there was also no evidence of nanoparticles in the brain, which indicates no apparent BBB disruption due to nanoparticle interaction. The particle accumulation effect is especially relevant in well-vascularized organs, where any malfunction leads to several impairments in the animal [53]. Based on this, we have focused on the particle effect over the liver and kidney, two commonly damaged organs due to particle accumulation or tissue disruption. For this purpose, GOT, GPT, and creatinine were analyzed in the blood at different time points for 14 days [54]. An increase of GOT and GPT enzymes in serum is related to liver damage $[55,56]$, while creatinine levels are associated with kidney malfunction [57]. No increments in GOT and GPT activity were observed in any of the groups compared to baseline levels. Creatinine levels were always under the detection limit $\left(<0.5 \mathrm{mg} \mathrm{dL}^{-1}\right)$ and no increments were observed in any of the groups or time points. On the other hand, all rats were observed for 1 month to control their activities in case of any respiratory failure or lethargic behavior, and all showed normal activity.

A

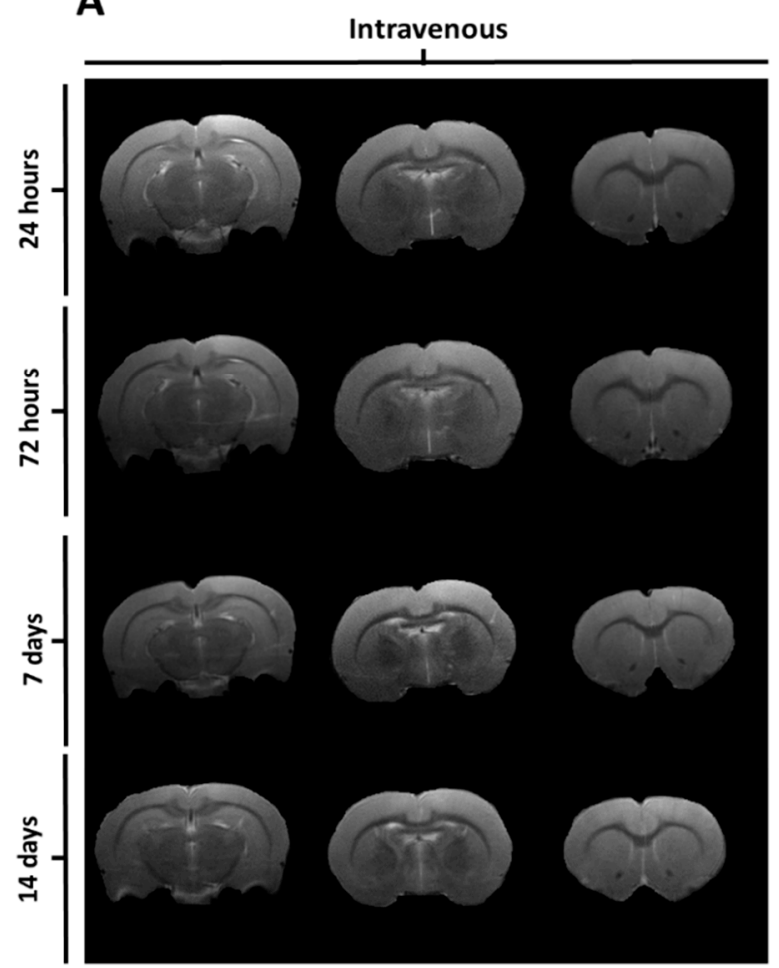

B

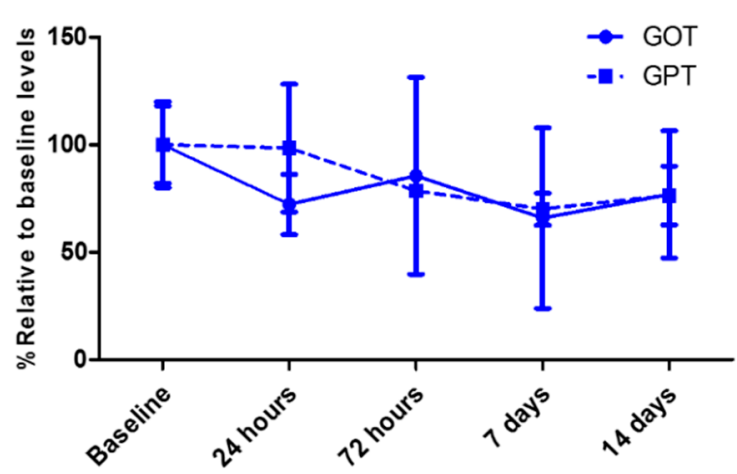

Intra-arterial

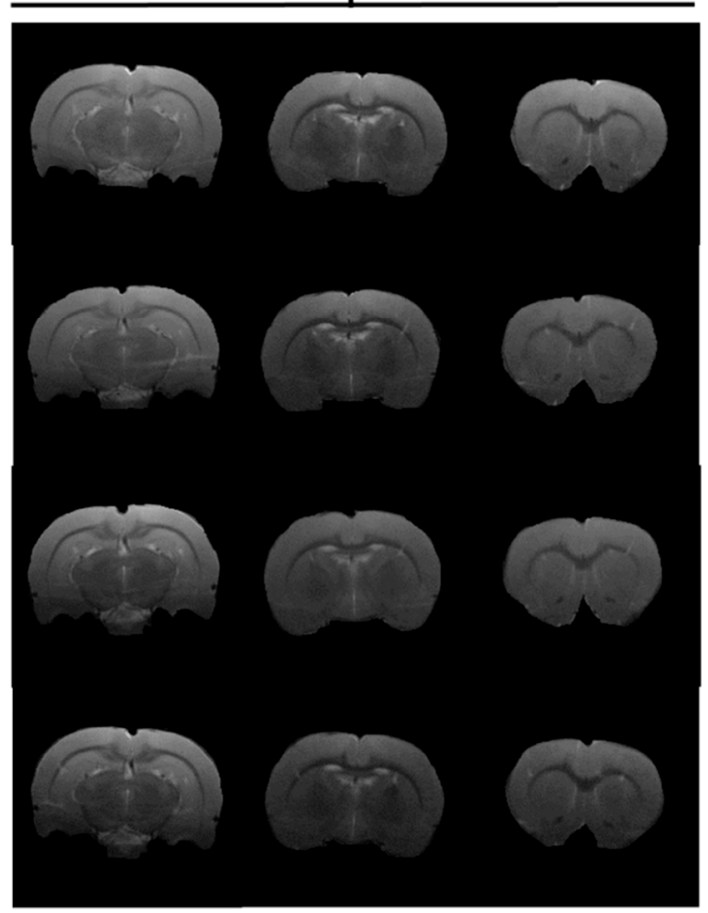

C

Intra-arterial administration

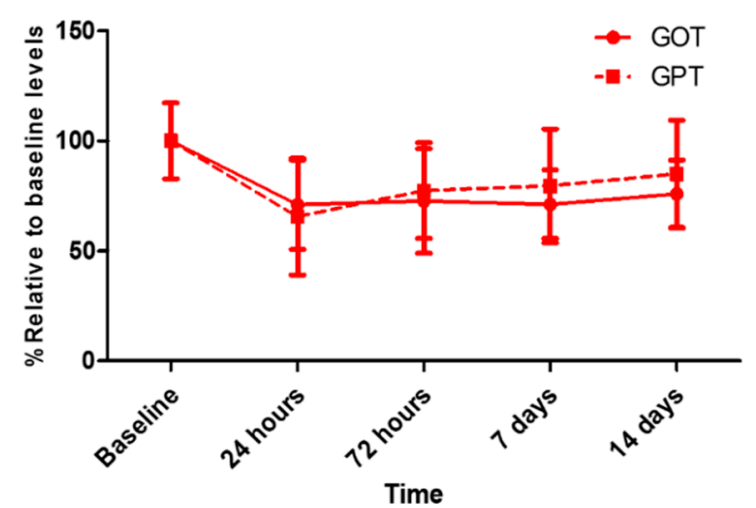

Figure 14. (A) $\mathrm{T} 2$ weight images after intravenous and intra-arterial administration of $1.4 \mathrm{mg} / \mathrm{kg}$ of HMMSN hybrid magnetic mesoporous nanorods. (B,C) GOT and GPT levels normalized to baseline at different time points after intravenous and intra-arterial administrations, respectively. ( $\mathrm{N}=3$ /group). 
Different parameters, such as charge, size, or shape, influence the cell-particle interaction [58], and can increase tropism determined by the cellular type or facilitate its clearance and blood circulation times. For instance, a positive charged particle increases the electrostatic attraction to the superficially negative cells, which causes an increase in the toxicity response, while a negative charge causes a greater phagocytosis of macrophages. Similar dualities are associated to size [59] and shape [60], with rod-like particles similar to that described in this work showing less uptake due to the extra energy needed by the cell to wrap the particle compared to spherical shapes [61]. However, when coated with antibodies or similar strategies for active targeting, rods show higher binding than spherical shapes [62]. This makes nanoparticles a highly versatile tool that allows modifications to be performed on the molecular structure to enhance some interactions and decrease others according to the target requirements.

This work has demonstrated a first approach for the safe use of rod shaped magnetic mesoporous nanorods at the concentrations described above, with no potential damage to endothelial brain cells, even showing an apparently high level of uptake. Magnetic resonance imaging showed no brain damage for 14 days, and no liver or kidney impairment, which evidences its safe use both in vitro and in vivo, overcoming toxicity impairments, and allowing its future use as a harmless contrast agent or therapeutic tool.

\section{Conclusions}

Multimodal mesoporous nanorods, with controlled morphology and size, were developed and studied, showing good magnetic performance for MRI contrast activity, intense fluorescent response, large specific surface area for high capacity loading, and a versatile surface for grafting biologically active moieties

In addition, an extended biocompatibility study was performed by analyzing the cell toxicity and organ status of male Sprague-Dawley rats after being injected with samples of nanorods by different administration routes (intravenous and intra-arterial), confirming that animals remained unaltered after the treatment with no organ disability.

In addition, intraparenquimal injection of nanorods corroborated their capacity as contrast agents in the brain due to a higher T2 signal intensity than usual, thus providing enhanced contrast. Likewise, using LDH assay, the Prussian Blue stain displayed a large nanorods' uptake that covered most of the cell cytoplasm, showing that only the higher concentration presented toxicity with respect to the control group.

This preliminary physicochemical and biological in vitro/in vivo study shows that magnetic mesoporous silica nanorods present a combination of properties that make them suitable candidates to be tested as multifunctional nanoreservoirs in brain endothelium applications.

Author Contributions: Conceptualization: J.R. and J.C.; supervision and formal analysis: Y.P. and F.C.; MRI characterization R.I.-R., investigation and development: Z.V.-O. and A.D.S.-C., supervision and validation: T.S.

Funding: This work was supported by the European Commission under the PANA project, Call H2020-NMP-2015-two-stage, Grant 686009, and partially supported by the Consellería de Educación Program for the Development of Strategic Grouping in Materials-AEMAT at the University of Santiago de Compostela under Grant No. ED431E2018/08, Xunta de Galicia, and Program for the Consolidation of Reasearch Units of Competitive Reference GRC2017, Grant N. ED431C 2017/22.

Conflicts of Interest: The authors declare no conflict of interest.

\section{Abbreviations}

BET Brunauer-Emmett-Teller method; BJH Barrett-Joyner-Halenda method; ECA elemental chemical analysis; FAAS flame atomic absorption spectroscopy; $\mathrm{Fe}_{3} \mathrm{O}_{4} @ \mathrm{OA}$ magnetite functionalized with oleic acid; FTIR Fourier-Transform Infrared Spectroscopy; GOT glutamate oxaloacetate transaminase enzyme; GPT glutamate pyruvate transaminase enzyme; HMMSN Hybrid Magnetic Mesoporous Silica Nanorods; LDH Lactate dehydrogenase; MRI Magnetic Resonance Imaging; SEM scanning electron microscopy; S15N SBA-15 mesoporous silica nanorods; TGA Thermogravimetric analysis; TEM transmission electron microscopy; VSM vibrating sample magnetometer; XRD X-ray diffraction. 


\section{References}

1. Meyers, J.D.; Doane, T.; Burda, C.; Basilion, J.P. Nanoparticles for Imaging and Treating Brain Cancer. Nanomedicine 2013, 8, 123-143. [CrossRef]

2. Bhojani, M.S.; Van Dort, M.; Rehemtulla, A.; Ross, B.D. Targeted Imaging and Therapy of Brain Cancer Using Theranostic Nanoparticles. Mol. Pharm. 2010, 7, 1921-1929. [CrossRef] [PubMed]

3. Lv, G.; Guo, W.; Zhang, W.; Zhang, T.; Li, S.; Chen, S.; Eltahan, A.S.; Wang, D.; Wang, Y.; Zhang, J.; et al. Near-Infrared Emission CuInS/ZnS Quantum Dots: All-in-One Theranostic Nanomedicines with Intrinsic Fluorescence/Photoacoustic Imaging for Tumor Phototherapy. ACS Nano 2016, 10, 9637-9645. [CrossRef] [PubMed]

4. Silva-Candal, A.; Argibay, B.; Iglesias-Rey, R.; Vargas, Z.; Vieites-Prado, A.; López-Arias, E.; Rodríguez-Castro, E.; López-Dequidt, I.; Rodríguez-Yáñez, M.; Piñeiro, Y.; et al. Vectorized Nanodelivery Systems for Ischemic Stroke: A Concept and a Need. J. Nanobiotechnol. 2017, 15, 30. [CrossRef] [PubMed]

5. Masserini, M. Nanoparticles for Brain Drug Delivery. ISRN Biochem. 2013, 2013, 238428. [CrossRef] [PubMed]

6. Baghirov, H.; Karaman, D.; Viitala, T.; Duchanoy, A.; Lou, Y.R.; Mamaeva, V.; Pryazhnikov, E.; Khiroug, L.; De Lange Davies, C.; Sahlgren, C.; et al. Feasibility Study of the Permeability and Uptake of Mesoporous Silica Nanoparticles across the Blood-Brain Barrier. PLoS ONE 2016, 11, e0160705. [CrossRef]

7. Posadas, I.; Monteagudo, S.; Ceña, V. Nanoparticles for Brain-Specific Drug and Genetic Material Delivery, Imaging and Diagnosis. Nanomedicine 2016, 11, 833-849. [CrossRef]

8. Saraiva, C.; Praça, C.; Ferreira, R.; Santos, T.; Ferreira, L.; Bernardino, L. Nanoparticle-mediated brain drug delivery: Overcoming blood-brain barrier to treat neurodegenerative diseases. Control. Release 2016, 235, 34-47. [CrossRef]

9. Ceña, V.; Játiva, P. Nanoparticle crossing of blood-brain barrier: A road to new therapeutic approaches to central nervous system diseases. Nanomedicine 2018, 13, 1513-1516. [CrossRef]

10. Vargas-Osorio, Z.; Argibay, B.; Piñeiro, Y.; Vázquez-Vázquez, C.; López-Quintela, M.A.; Álvarez-Perez, M.A.; Sobrino, T.; Campos, F.; Castillo, J.; Rivas, J. Multicore Magnetic $\mathrm{Fe}_{3} \mathrm{O}_{4} @ \mathrm{C}$ Beads with Enhanced Magnetic Response for MRI in Brain Biomedical Applications. IEEE Trans. Magn. 2016, 52, 2300604. [CrossRef]

11. Hao, X.; Hu, X.; Zhang, C.; Chen, S.; Li, Z.; Yang, X.; Liu, H.; Jia, G.; Liu, D.; Ge, K.; et al. Hybrid Mesoporous Silica-Based Drug Carrier Nanostructures with Improved Degradability by Hydroxyapatite. ACS Nano 2015, 9, 9614-9625. [CrossRef] [PubMed]

12. Peng, J.R.; Qi, T.T.; Liao, J.F.; Chu, B.Y.; Yang, Q.; Qu, Y.; Li, W.T.; Li, H.; Luo, F.; Qian, Z.Y. Mesoporous Magnetic Gold "nanoclusters" as Theranostic Carrier for Chemo-Photothermal Co-Therapy of Breast Cancer. Theranostics 2014, 4, 678-692. [CrossRef] [PubMed]

13. Sahoo, B.; Devi, K.S.P.; Dutta, S.; Maiti, T.K.; Pramanik, P.; Dhara, D. Biocompatible Mesoporous Silica-Coated Superparamagnetic Manganese Ferrite Nanoparticles for Targeted Drug Delivery and MR Imaging Applications. J. Colloid Interface Sci. 2014, 431, 31-41. [CrossRef]

14. Vargas-Osorio, Z.; Luzardo-Álvarez, A.; Piñeiro, Y.; Vázquez-Vázquez, C.; Gómez-Amoza, J.L.; Blanco-Méndez, J.; Otero Espinar, F.J.; Rivas, J. 3D Hybrid Mesoporous Scaffolds for Simvastatin Sustained Delivery With in Vitro Cell Compatibility. ACS Omega 2019. [CrossRef]

15. Giri, S.; Trewyn, B.G.; Stellmaker, M.P.; Lin, V.S.Y. Stimuli-Responsive Controlled-Release Delivery System Based on Mesoporous Silica Nanorods Capped with Magnetic Nanoparticles. Angew. Chem. Int. Ed. 2005, 44, 5038-5044. [CrossRef] [PubMed]

16. Khan, W.; Hosseinkhani, H.; Ickowicz, D.; Da Hong, P.; Yu, D.S.; Domb, A.J. Polysaccharide Gene Transfection Agents. Acta Biomater. 2012, 8, 4224-4232. [CrossRef] [PubMed]

17. Hartono, S.B.; Yu, M.; Gu, W.; Yang, J.; Strounina, E.; Wang, X.; Qiao, S.; Yu, C. Synthesis of Multi-Functional Large Pore Mesoporous Silica Nanoparticles as Gene Carriers. Nanotechnology 2014, 25, 55701. [CrossRef] [PubMed]

18. Zhou, P.; Cheng, X.; Xia, Y.; Wang, P.; Zou, K.; Xu, S.; Du, J. Organic/inorganic Composite Membranes Based on Poly(l-Lactic-Co-Glycolic Acid) and Mesoporous Silica for Effective Bone Tissue Engineering. ACS Appl. Mater. Interfaces 2014, 6, 20895-20903. [CrossRef] [PubMed] 
19. Bañobre-lópez, M.; Piñeiro-redondo, Y.; Sandri, M.; Tampieri, A.; De Santis, R.; Dediu, V.A.; Rivas, J. Hyperthermia Induced in Magnetic Scaffolds for Bone Tissue Engineering. IEEE Trans. Magn. 2014, 50, 5400507. [CrossRef]

20. Piñeiro, Y.; Vargas, Z.; Rivas, J.; López-Quintela, M.A. Iron Oxide Based Nanoparticles for Magnetic Hyperthermia Strategies in Biological Applications. Eur. J. Inorg. Chem. 2015, 2015, 4495-4509. [CrossRef]

21. Wu, S.H.; Lin, Y.S.; Hung, Y.; Chou, Y.H.; Hsu, Y.H.; Chang, C.; Mou, C.Y. Multifunctional Mesoporous Silica Nanoparticles for Intracellular Labeling and Animal Magnetic Resonance Imaging Studies. ChemBioChem 2008, 9, 53-57. [CrossRef] [PubMed]

22. Souza, K.C.; Mohallem, N.D.S.; Sousa, E.M.B. Mesoporous Silica-Magnetite Nanocomposite: Facile Synthesis Route for Application in Hyperthermia. J. Sol-Gel Sci. Technol. 2010, 53, 418-427. [CrossRef]

23. Khairy, M.; El-Safty, S.A.; Ismael, M.; Kawarada, H. Mesoporous NiO Nanomagnets as Catalysts and Separators of Chemical Agents. Appl. Catal. B Environ. 2012, 127, 1-10. [CrossRef]

24. Lin, J.; Chu, P.; Wei, Z. A New Dual Immunoassay for Tumor Markers Based on Chemiluminescence Signal Amplification by Magnetic Mesoporous Silica and Enzyme Modified Gold Nanoparticles. Anal. Sci. 2012, 28, 21. [CrossRef]

25. Zhao, G.; Wang, J.; Li, Y.; Huang, H.; Chen, X. Reversible Immobilization of Glucoamylase onto Metal-Ligand Functionalized Magnetic FeSBA-15. Biochem. Eng. J. 2012, 68, 159-166. [CrossRef]

26. Xuan, S.; Wang, F.; Lai, J.M.Y.; Sham, K.W.Y.; Wang, Y.J.; Lee, S.; Yu, J.C.; Cheng, C.H.K.; Leung, K.C. Synthesis of Biocompatible, Mesoporous $\mathrm{Fe}_{3} \mathrm{O}_{4} \mathrm{Nano} /$ Microspheres with Large Surface Area for Magnetic Resonance Imaging and Therapeutic Applications. ACS Appl. Mater. Interfaces 2011, 3, 237-244. [CrossRef]

27. Yang, P.; Gai, S.; Lin, J. Functionalized Mesoporous Silica Materials for Controlled Drug Delivery. Chem. Soc. Rev. 2012, 41, 3679. [CrossRef]

28. Chen, Y.; Wang, Q.; Wang, T. Facile Large-Scale Synthesis of Brain-like Mesoporous Silica Nanocomposites via a Selective Etching Process. Nanoscale 2015, 7, 16442-16450. [CrossRef] [PubMed]

29. Kim, I.Y.; Joachim, E.; Choi, H.; Kim, K. Toxicity of Silica Nanoparticles Depends on Size, Dose, and Cell Type. Nanomed. Nanotechnol. Biol. Med. 2015, 11, 1407-1416. [CrossRef]

30. Huang, X.; Li, L.; Liu, T.; Hao, N.; Liu, H.; Chen, D.; Tang, F. The Shape Effect of Mesoporous Silica Nanoparticles on Biodistribution, Clearance, and Biocompatibility in Vivo. ACS Nano 2011, 5, 5390-5399. [CrossRef]

31. Liu, X.; Wang, Y.; He, J.; Wang, X.M.; Cui, F.Z.; Xu, Q.Y. Various Fates of Neuronal Progenitor Cells Observed on Several Different Chemical Functional Groups. Front. Mater. Sci. 2011, 5, 358-366. [CrossRef]

32. Wang, Y.; Zhang, F.; Wang, Y.; Ren, J.; Li, C.; Liu, X.; Guo, Y.; Guo, Y.; Lu, G. Synthesis of length controllable mesoporous SBA-15 rods. Mater. Chem. Phys. 2009, 115, 649-655. [CrossRef]

33. Vargas-Osorio, Z.; González-Gómez, M.A.; Piñeiro, Y.; Vázquez-Vázquez, C.; Rodríguez-Abreu, C.; López-Quintela, M.A.; Rivas, J. Novel Synthetic Routes of Large-Pore Magnetic Mesoporous Nanocomposites (SBA-15/ $\mathrm{Fe}_{3} \mathrm{O}_{4}$ ) as Potential Multifunctional Theranostic Nanodevices. J. Mater. Chem. B 2017, 5, 9395-9404. [CrossRef]

34. Sing, K.S.W.; Everett, D.H.; Haul, R.A.W.; Moscou, L.; Pierotti, R.A.; Rouquérol, J.; Siemieniewska, T. International union of pure commission on colloid and surface chemistry including catalysis * reporting physisorption data for gas/solid systems with special reference to the determination of surface area and porosity. Pure Appl. Chem. 1984, 57, 2201-2218.

35. Rath, D.; Rana, S.; Parida, K.M. Organic Amine-Functionalized Silica-Based Mesoporous Materials: An Update of Syntheses and Catalytic Applications. RSC Adv. 2014, 4, 57111-57124. [CrossRef]

36. Hoffmann, F.; Fröba, M. Vitalising Porous Inorganic Silica Networks with Organic functions-PMOs and Related Hybrid Materials. Chem. Soc. Rev. 2011, 40, 608-620. [CrossRef]

37. Johansson, E.M.; Ballem, M.A.; Córdoba, J.M.; Odén, M. Rapid Synthesis of SBA-15 Rods with Variable Lengths, Widths, and Tunable Large Pores. Langmuir 2011, 27, 4994-4999. [CrossRef] [PubMed]

38. Vasil'ev, S.G.; Volkov, V.I.; Tatarinova, E.A.; Muzafarov, A.M. A Solid-State NMR Investigation of MQ Silicone Copolymers. Appl. Magn. Reson. 2013, 44, 1015-1025. [CrossRef] [PubMed] 
39. Wiench, J.W.; Avadhut, Y.S.; Maity, N.; Bhaduri, S.; Lahiri, G.K.; Pruski, M.; Ganapathy, S. Characterization of Covalent Linkages in Organically Functionalized MCM-41 Mesoporous Materials by Solid-State NMR and Theoretical Calculations. J. Phys. Chem. B 2007, 111, 3877-3885. [CrossRef]

40. Liu, Y.; Chen, R.; Yuan, D.; Liu, Z.; Meng, M.; Wang, Y.; Han, J.; Meng, X.; Liu, F.; Hu, Z.; et al. Thermal-Responsive Ion-Imprinted Polymer Based on Magnetic Mesoporous Silica SBA-15 for Selective Removal of Sr(II) from Aqueous Solution. Colloid Polym. Sci. 2014, 293, 109-123. [CrossRef]

41. Zhu, Y.; Kaskel, S.; Ikoma, T.; Hanagata, N. Magnetic SBA-15/poly(N-Isopropylacrylamide) Composite: Preparation, Characterization and Temperature-Responsive Drug Release Property. Microporous Mesoporous Mater. 2009, 123, 107-112. [CrossRef]

42. Huang, S.S.; Yang, P.P.; Cheng, Z.Y.; Li, C.X.; Fan, Y.; Kong, D.Y.; Lin, J. Synthesis and Characterization of Magnetic $\mathrm{Fe}_{\mathrm{x}} \mathrm{O}_{\mathrm{y}} @$ SBA-15 Composites With Different Morphologies for Controlled Drug Release and Targeting. J. Phys. Chem. C 2008, 112, 7130-7137. [CrossRef]

43. Yu, L.; Yang, X.; Wang, D. $\mathrm{TiO}_{2}$ Incorporated in Magnetic Mesoporous SBA-15 by a Facile Inner-Pore Hydrolysis Process toward Enhanced Adsorption-Photocatalysis Performances for As(III). J. Colloid Interface Sci. 2015, 448, 525-532. [CrossRef] [PubMed]

44. Escobar Zapata, E.V.; Martínez Pérez, C.A.; Rodríguez González, C.A.; Castro Carmona, J.S.; Quevedo Lopez, M.A.; García-Casillas, P.E. Adherence of Paclitaxel Drug in Magnetite Chitosan Nanoparticles. J. Alloys Compd. 2012, 536, S441-S444. [CrossRef]

45. Khandhar, A.P.; Ferguson, R.M.; Krishnan, K.M. Monodispersed Magnetite Nanoparticles Optimized for Magnetic Fluid Hyperthermia: Implications in Biological Systems. J. Appl. Phys. 2011, 109, 7-9. [CrossRef] [PubMed]

46. Kechrakos, D.; Trohidou, K.N. Dipolar Interaction Effects in the Magnetic and Magnetotransport Properties of Ordered Nanoparticle Arrays. J. Nanosci. Nanotechnol. 2008, 8, 2929-2943. [PubMed]

47. Berkowitz, A.E.; Takano, K. Exchange Anisotropy-A Review. J. Magn. Magn. Mater. 1999, 200, 552-570. [CrossRef]

48. Wang, Y.-X. Superparamagnetic Iron Oxide Based MRI Contrast Agents: Current Status of Clinical Application. Quant. Imaging Med. Surg. 2011, 1, 35-44.

49. Duan, J.; Yu, Y.; Yu, Y.; Li, Y.; Wang, J.; Geng, W.; Jiang, L.; Li, Q.; Zhou, X.; Sun, Z. Silica Nanoparticles Induce Autophagy and Endothelial Dysfunction via the PI3K/Akt/mTOR Signaling Pathway. Int. J. Nanomed. 2014, 9, 5131-5141. [CrossRef]

50. Orlando, A.; Cazzaniga, E.M.; Tringali, M.; Gullo, F.; Becchetti, A.; Minniti, S.; Taraballi, F.; Tasciotti, E.; Re, F. Mesoporous Silica Nanoparticles Trigger Mitophagy in Endothelial Cells and Perturb Neuronal Network Activity in a Size- and Time-Dependent Manner. Int. J. Nanomed. 2017, 12, 3547-3559. [CrossRef] [PubMed]

51. Fröhlich, E. The Role of Surface Charge in Cellular Uptake and Cytotoxicity of Medical Nanoparticles. Int. J. Nanomed. 2012, 7, 5577-5591. [CrossRef]

52. Yildirimer, L.; Thanh, N.T.K.; Loizidou, M.; Seifalian, A.M. Toxicological Considerations of Clinically Applicable Nanoparticles. Nano Today 2011, 6, 585-607. [CrossRef] [PubMed]

53. Parivar, K.; Malekvand Fard, F.; Bayat, M.; Alavian, S.M.; Motavaf, M. Evaluation of Iron Oxide Nanoparticles Toxicity on Liver Cells of BALB/c Rats. Iran. Red Crescent Med. J. 2016, 18, 1-5. [CrossRef]

54. Abdelhalim, M.A.K.; Abdelmottaleb Moussa, S.A. The Gold Nanoparticle Size and Exposure Duration Effect on the Liver and Kidney Function of Rats: In Vivo. Saudi J. Biol. Sci. 2013, 20, 177-181. [CrossRef] [PubMed]

55. Adeyemi, O.S.; Adewumi, I. Biochemical Evaluation of Silver Nanoparticles in Wistar Rats. Int. Sch. Res. Not. 2014, 2014, 196091. [CrossRef] [PubMed]

56. Kim, W.R.; Flamm, S.L.; Di Bisceglie, A.M.; Bodenheimer, H.C. Serum Activity of Alanine Aminotransferase (ALT) as an Indicator of Health and Disease. Hepatology 2008, 47, 1363-1370. [CrossRef] [PubMed]

57. Ajdary, M.; Ghahnavieh, M.Z.; Naghsh, N. Sub-Chronic Toxicity of Gold Nanoparticles in Male Mice. Adv. Biomed. Res. 2015, 4, 67. [CrossRef]

58. Verma, A.; Stellacci, F. Effect of Surface Properties on Nanoparticle-Cell Interactions. Small 2010, 6, 12-21. [CrossRef] [PubMed]

59. Jiang, W.; Kim, B.Y.S.; Rutka, J.T.; Chan, W.C.W. Nanoparticle-Mediated Cellular Response Is Size-Dependent. Nat. Nanotechnol. 2008, 3, 145-150. [CrossRef]

60. He, Y.; Park, K. Effects of the Microparticle Shape on Cellular Uptake. Mol. Pharm. 2016, 13, $2164-2171$. [CrossRef] 
61. Li, Y.; Kröger, M.; Liu, W.K. Shape Effect in Cellular Uptake of PEGylated Nanoparticles: Comparison between Sphere, Rod, Cube and Disk. Nanoscale 2015, 7, 16631-16646. [CrossRef] [PubMed]

62. Kolhar, P.; Anselmo, A.C.; Gupta, V.; Pant, K.; Prabhakarpandian, B.; Ruoslahti, E.; Mitragotri, S. Using Shape Effects to Target Antibody-Coated Nanoparticles to Lung and Brain Endothelium. Proc. Natl. Acad. Sci. USA 2013, 110, 10753-10758. [CrossRef] [PubMed]

(C) 2019 by the authors. Licensee MDPI, Basel, Switzerland. This article is an open access article distributed under the terms and conditions of the Creative Commons Attribution (CC BY) license (http:/ / creativecommons.org/licenses/by/4.0/). 